Portland State University

PDXScholar

1974

\title{
A study of ambulance transportation in relation to public welfare policy
}

Gary Jules Lutz

Portland State University

Follow this and additional works at: https://pdxscholar.library.pdx.edu/open_access_etds

Part of the Medicine and Health Commons, Social Welfare Commons, and the Social Work Commons Let us know how access to this document benefits you.

\section{Recommended Citation}

Lutz, Gary Jules, "A study of ambulance transportation in relation to public welfare policy" (1974). Dissertations and Theses. Paper 1761.

https://doi.org/10.15760/etd.1760

This Thesis is brought to you for free and open access. It has been accepted for inclusion in Dissertations and Theses by an authorized administrator of PDXScholar. Please contact us if we can make this document more accessible: pdxscholar@pdx.edu. 
A STUDY OF AMBULANCE TRANSPORTATION

IN RELATION TO PUBLIC WELFARE POLICY

by

GARY JULES LUTZ

a report submitted in partial fulfillment of the requirements for the degree of

MASTER OF

SOCIAL WORK

Portland State University 1974

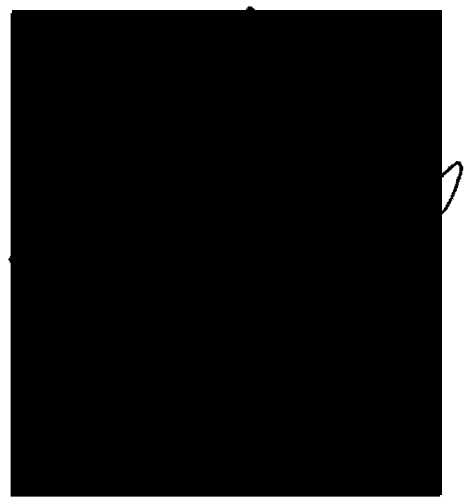


FOREWORD

This study examines the Public Welfare Medical Transportation Program with particular focus on ambulance transportation. It addresses the problems Public Welfare has in funding and administrating the program, looks at the components of the larger emergency medical care system and its relationship to Public Welfare, studies who, how, and why this service is being delivered, and makes recommendations for policy revision in respect to the larger emergency medical care system. 


\section{ACKNOWLEDGMENTS}

A study such as this cannot be anything less than the product of contributions in mind, effort and support from many people. This study owes its inception to John Burch who gave knowledge and support throughout the study, Sondra Lippman who helped with the statistics, Dr. James Landis who processed the evaluation of medical assessments, and William Niebert, Clarence Cook, and Christopher Onslow who helped in providing knowledge and data about the ambulance transportation system. My appreciation goes to Freddie Petite for allowing me access to the records at City Hall and also for supplying pertinent information. Also I am indebted to many other people throughout the city and the medical care system in their contributions in knowledge, information and material.

My appreciation goes to my wife, Diana, who helped in editing and gave me emotional support throughout this process, and to the Welfare clerical staff who did the typing. 
TABLE OF CONTENTS

PAGE

FOREWORD . . . . . . . . . . . . . . . . . . . ${ }_{\mathrm{i}}$

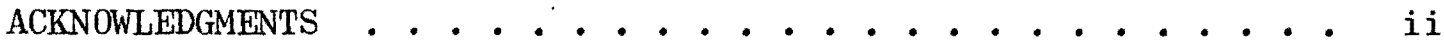

LIST OF TABLES . . . . . . . . . . . . . . . . . vii

CHAPTER

I INTRODUCTION . . . . . . . . ....... 1

Scope of Study . . . . . . . . . . . . 1

Referral System

Other Perceived Issues

The Sample

Interviews

Other Research

Description of Agency .. . . . . . . 7

01d Age Assistance

Aid to the Blind

Aid to the Disabled

Aid to Dependent Children

General Assistance

Description of Program .......... . . 9

Medical Assistance

Medical Transportation

Description of West Branch ......... 10

References ................. 14

II DESCRIPTION OF THE PROBLEM . . . . . . . . . . 15

Cost . . . . . . . . . . . . . 16

Summary . . . . . . . . . . 22 
Vagueness in the Program Policies and Guidelines .. . . . . . . . 23

Lack of Control in the Delivery of Service ............ . 24

Inadequate Research Data and Information .......... . 26

Inability to Initiate Change . . . . . . . 26

County Physician's Office Authorizations Police Fmergency Nursing Home Ambulances

References .............. . . 32

III EMERGENCY HEALTH SERVICES . . . . . . . . . . . 33

Ambulance Companies ........... 33

The Portland City Club Report

Hospital Fmergency Treatment Units . . . . . . 39

The Portland City Club Report

Comprehensive Health Planning Association Report

Police...................

Comprehensive Health $\mathrm{Pl}$ anning Association Report

Mayor's Policy Statement

The Medical Profession . . . . . . . . . 46

The Public . . . . . . . . . . . . 48

Education and Information

Reporting, Dispatching and Coordinating Emergency Problems

David P. Hooper Alcoholic Recovery Center . . . 53 References................ 55 
IV WEST BRANCH STUDY . . . . . . . . . . . . . . 57

Definitions of Terms . . . . . . . . . . 57

Programs

Origin-Destination

Referrals

Medical-Transfer

Admissions

Origin and Destination . . . . . . . . . 59

Points of Origin and Destination

Points of Origin and Destination

Compared to Program

Users of Ambulance Transportation . . . . . . 62

Users of Ambulance in each Program Age

Ambulance Referrals . . . . . . . . . . 64

Referrals compared with Origin and

$$
\text { Destination }
$$

Referrals compared to Programs

Referrals compared to the Reason

for Ambulance transportation

Temporal Breakdown for Ambulance Transportation.

Requests for Ambulances during and after Office Hours

Time of Request for Ambulance

Seasonal Patterns

Repeats . . . . . . . . . . . . . ${ }^{1} 72$

Repeats compared with Referrals

Repeats compared with Programs

Cost .................. 74

Medical Assessment ............ 75

Medical Assessment compared with Admissions and Transfers 
Medical Assessment (continued) ..........

Medical Assessment compared with Lights and Sirens

Medical Assessment compared with Programs

Medical Assessment compared with Referrals

Admi ssions and Transfers . . . . . . . . 80

Admissions and Transfers compared with Lights and Sirens

Admissions and Transfers compared with Programs

Admi ssions and Transfers compared with Referrals

V ANALYSIS AND RECOMMENDATIONS . . . . . . . . . 84

Welfare's present program . . . . . . . 84

Rule two - Authorization

Rule three - Emergent Transportation

Rule four - Type of Transportation

Rule five - Public Rates

Emergency Health Services . . . . . . . 91

Ambulances

Hospital Emergency Treatment Units

Police

The Medical Profession

The Public

David P. Hooper Alcoholic Recovery Center

West Branch Study ............ . 94

Conclusion ................. 96

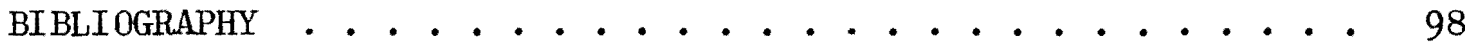

APPENDIX ...................................... 100 


\section{LIST OF TABLES}

TABLE

PAGE

I West Branches Program Population Compared to District and State . . . . . . . . . 11

II Percentage of Program Populations - West of District - District of State . . . . . . . . 12

III State Medical Transportation Costs . . . . . . . 16

IV Multnomah County District Medical Transportation Costs ... 17

V Total Persons Eligible for Medical Assistance . . . . 18

VI Percent of Expense per Mode of Transportation for State . . ............... 19

VII Breakdown of West Branches Expense per Mode of Transportation ............. . . 20

VIII Ambulance Users and Cost for Public Welfare Division . . 21

IX Ambulance Rates . . . . . . . . . . . . 22

$\mathrm{X} \quad$ Origin and Destination . . . . . . . . . 59

XI Source and Destination compared with Program . . . . . 61

XII Usexs of Ambulances by Program ............ 63

XIII Age of Ambulance users by Program .......... 64

XIV Referrals Compared with Origin and Destination ..... 65

XV Number of Cases by Referral Source and Program . . . . . 67

XVI The Percent of Medical and Transfer Cases by Referral Source .............. 68

XVII Percent of Transfer and Medical Cases within

Each Program ............. 69

XVIII Cases Referred During and After Office Hours

By Source . . . . . . . . . . . . . 70 
viii

TABLE

PAGE

XIX Number of Cases by Time of Service . . . . . . . 71

XX Seasonal Patterns Compared with Programs . . . . . . 72

XXI Average Number of Repeats per Person by

Referral Source . . . . . . . . . 73

XXII Repeats Compared with Programs . . . . . . . . 74

XXIII Cost per Trip . . . . . . . . . . . 75

XXIV Medical Assessment compared with Admissions

and Transfers ............ . 76

XXV Medical Assessment compared with Lights

and Sirens . . . . . . . . . . . . 78

XXVI Medical Assessment compared with Programs . . . . . . 79

XXVII Medical Assessment compared with Referral . . . . . 80

XXVIII Admissions and Transfers compared with

Lights and Sirens . . . . . . . . . . 81

XXIX Admissions and Transfers compared with Program . . . . 82

XXX Admissions and Transfers compared with Referral . . . 83 
CHAPTER I

INTRODUCTION

This report is an outgrowth of increasing concern by Public Welfare administrators and staff over the efficiency and effectiveness of the Medical Transportation Program. It is an attempt to clarify the problems Public Welfare has in funding and setting policy for those delivering this service. Also it is an attempt to depict various components of the emergency health service system, their representatives and constituencies, that Public Welfare must consider if à change proposal is made and implemented. Particular emphasis is focused on ambulance transportation as this transportation modality has been considered by many as the most problematic in the Medical Transportation Program.

\section{SCOPE OF STUDY}

It was suggested by the Multnomah County District Manager for Public Welfare that this study address itself specifically to ambulance transportation, to critique Public Welfare's policy in the delivery of this social service, to survey when, what, how, and why this social service is being delivered, and to make recommendations for a change proposal on policy if appropriate. However, it was felt that ambulances cannot be considered in a vacuum, nor can or should Public Welfare policy revision be considered or implemented without taking into consideration 
the impact on the larger system. Therefore other areas and components of the emergency medical care system, their representatives and constituencies will be discussed also.

\section{$\underline{\text { Referral System }}$}

Police Referrals. In the planning phase of this study there was much concern by Welfare staff over police referrals for ambulances. It was felt that they were misusing the system tremendously, calling for an ambulance whenever the situation involved medical attention of any kind. Of particular concern was their handling "the man down on the street", the inebriated or alcoholic. Since the passage of Senate Bill 431 in 1971, the establishment of the David P. Hooper Alcoholic Recovery Center was recognized as an alternative method of treatment for the public inebriate. The passage of this bill repealed all laws making drinking in public, public drunkeness, and vagrancy or disorderly conduct where inebriation is a primary contributor a crime. This has changed police strategy somewhat. It was felt since alcoholism was no longer a crime but an illness, police were shipping the alcoholics to the hospital via ambulance and not utilizing the Detoxification Center.

Interview were held with police and the Detoxification Center's staff. Letters were mailed to a sample of five cities similar to Portland in population, industry, and social characteristic indexes in an attempt to find out what other cities were doing in relationship to the inebriate. The cities which responded were: San Bernardino, California; Indi anapolis, Indiana; Columbus, Ohio; New Orleans, Louisiana; and Miami, Florida.

Other Referrals. Other referrals were classified into three major 
groups: Private, County Physician's Office and Welfare. Private referrals pertain to ambulances requested by the Welfare recipient, the public, or nursing homes. There was a feeling by the Welfare staff that private referrals were second to police in misusing ambulances by waiting until after Welfare's office hours to request an ambulance, thus avoiding the need to obtain prior authorization. It was felt by Welfare staff that in many of these cases the medical need did not substantiate the transportation modality. The County Physician's Office was perceived by Welfare staff as using ambulances primarily for transferring a patient from one hospital to another or from hospital to nursing home. This they felt was an inappropriate usage of ambulance transportation. Because of the low number of prior authorized Welfare referrals, this referral system was not seen as problematic.

Other Perceived Issues

Point of Pick-up and Destination. It was felt by the Welfare staff Welfare recipients were not taken to the nearest hospital, thus increasing transportation costs.

Repeaters. There was some concern by Welfare staff over frequent use of ambulance transportation by Welfare recipients.

Costs. There was interest at the State level of Public Welfare in cost variations for ambulance service in different areas throughout the state. It was felt by many Welfare staff that ambulance companies in Portland were over-charging for the services that they were rendering.

\section{The Sample}

In an attempt to address some of the above issues, a study was 
done at West Branch, Multnomah County Public Welfare. Since this Branch had approximately $44 \%$ of the medical transportation expense in the District, it was felt that any program changes should begin there. If the results of the study were such that they could not be used by the District or State, the findings would give the Branch some direction or substantiate its present service delivery system.

The population drawn from was approximately 1400 ambulance invoices. These were the paid invoices, filed alphabetically by year. Beginning with a random start and pulling every tenth invoice, 139 cases were obtained. Because of the nature of the filing system, there are some deviations in the sampling process that should be noted. First the filing system began July 1, 1972, which consisted of all invoices paid after that date. Invoices paid before that time were filed in the old system and did not constitute part of the sample. Some of the invoices sampled were thus from services rendered in previous months. The invoices were only current with the oldest service date drawn in the sample beginning June 4, 1972 .

At the other end of the time continuum there is also a deviation. The sample was pulled in the first week of November, 1973, meaning only those invoices that were paid at that time were sampled. The latest service date pulled was 0ctober 20, 1973.

Another deviation in the sampling process was the way "repeaters" were tabulated. Since tabulation of "repeaters"did not occur until the end of January, 1974, after the 1973 invoices were closed out, there was a different time period for this tabulation. This was done by counting the number of invoices filed under each of the sampled recipients for 
1972 and 1973. This means that the"repeater"tabulation covers a period of approximately one year and six months.

Information gathered in the sample included what program the Welfare recipient was in (old Age, Aid to the Blind, Aid to the Disabled, Aid to Dependent Children, and General Assistance), the date and time of service, who made the referral for ambulance service (Police, Welfare, Private, or County Physician's Office), amount charged, ambulance code (lights, no lights), nature of service (medical or transfer), date of birth, number of times ambulances were used by the recipient during the previously discussed time framework, and whether the Welfare recipient was admitted into a hospital or not.

An assessment of the patient's condition made by the ambulance medical technician at the time of pick-up was obtained. This assessment is useful as it is an inbetween perception between a layman's perception and a professional diagnosis of the medical condition of a person at the point and time of pick-up.

Ideally it would have been very useful and informative to have obtained two other categories on perceptions of medical need. The first would have been the perception of the person requesting the ambulance as to what was thought to be the condition of the person being transported, and why that person chose to call an ambulance. Since names were not recorded, this was impossible. The second category would have been to obtain the medical diagnosis of the person when delivered to the hospital. This was attempted; however, the Multnomah County Hospital Staff did not wish to take the time to pull the requested information themselves, nor would they allow this researcher access to the files in fear of jeopardizing confidentiality. Apparently they did not feel, 
as it was stated, that this research project was important enough. Since ninety of the one hundred and thirty nine cases were ambulance transportation from or to this hospital, no other attempt was made to gather information in this category from the other hospitals who appeared more responsive to the request.

The ambulance medical technicians assessments were evaluated by James Landis, M.D., Medical Director of Public Welfare, as to whether he felt the ambulance was or was not needed, or if he was uncertain. The results were tabulated and then used as an independent variable matched with other variables such as admissions, ambulance lights, transfers, etc., to attempt to come up with other key indicators of need for ambulance transportation. This process will be fully explained in a later chapter.

There were several attempts to enlist the support of the Multnomah County Medical Society to do a crosscheck on these assessments. A letter and several phone calls only instilled skepticism and left no other convenient alternative but to rely on Dr. Landis's judgement alone.

\section{Interviews}

Interviews were conducted with representatives of hospital administrations and staff, government agencies, business supplying ambulance companies, various organizations, and Public Welfare staff at the Branch, District and State levels.

\section{Other Research}

The following study and reports were reviewed and will be referred to throughout this report: 
1. "Report on Emergency Care to the Injured and Stricken in the Portland Area", by Portland City Club, 1966, and the follow-up report.in 1970 .

2. "Mayor's Policy Statement on Emergency Ambulance Care", by Douglas Capps, September 29, 1973.

3. "Report of the Committee on Emergency Medical Care Systems in Clackamas, Multnomah and Washington Counties", by the Comprehensive Health Planning Association for the Metropolitan Portland Area, 1971.

4. "The First Step", David P. Hooper Alcoholic Recovery Center follow-up evaluation prepared by the office of PEPD, June 25, 1973.

5. Unpublished ambulance transportation study done by John Burch, Multnomah County Public Welfare, August 24, 1970.

In addition, press reports were reviewed, magazine articles, and other related materials such as correspondence to the Portland Mayor's Office and correspondence within the Public Welfare system.

Other data was obtained through the Statistics Department of Public Welfare in Salem and the District and Branch offices.

\section{DESCRIPTION OF AGENCY}

Public Welfare is a program that has been established by federal law to provide supportive elements to those in need who cannot function adequately on their own. The programs Public Welfare offers are built largely upon the Social Security Act of 1935. This enabled the Federal Government to give grant-in-aid to the states who would issue direct cash payments to groups of needy people. In 1956 the Federal Government began helping states with costs of services to people in addition to cash payments, and in 1965 the Medicare Law created a Medical Assistance 
Program for people of all ages who need help with medical care. (1)*

Through the years the Social Security Act has been gradually broadened, with the Federal Government sharing up to $80 \%$ of the cost of the following groups of needy people under Public Welfare auspices:

0ld Age Assistance (ORS Ch. 413) ${ }^{(2)}$

The purpose of OAA is to insure that needy aged persons over 65 years of age have sufficient income available to enable them to live at a standard compatible with decency, and health, and necessary services to help them care for themselves as well as they can. The specific eligibility requirement is that they must be over 65 years of age. Aid To The Blind (ORS Ch. 412) (3)

The purpose of $A B$ is to insure that needy blind persons are provided with funds to live at a standard compatible with decency and health, and services to help them toward self-support or self care in accord with individual capacity. The specific eligibility requirement is that they must be a blind person as defined in ORS 412.995 .

Aid To The Disabled (ORS Ch. 412)

The purpose of $A D$ is to insure that needy disabled persons will be provided with sufficient funds to maintain a standard of living compatible with standards of decency and health, and services directed toward rehabilitation as far as individual capacity permits. The specific eligibility requirements are that they must be 18 years or older, must be disabled as verified by medical and social findings. The impairment

* Numbers refer to references listed at end of Chapters. 
must be one of major importance to substantially prevent the individual from engaging in useful occupations within his competence.

Aid To Dependent Children (ORS Ch. 418) ${ }^{(5)}$

The purpose of $\mathrm{ADC}$ is to provide funds for the care of children, usually in the home of parents or relatives, when they are in need due to death, continued absence, incapacity, or unemployment of a parent. The program is intended to strengthen family life and to help families become self-supporting wherever possible. The specific eligibility requirements are that the children must be under 18 years of age, or under 21 and attending school or vocational training. General Assistance (ORS Ch. 414)

The purpose of GA is to extend assistance, medical care and services to persons in need due to illness, unemployment, etc., who do not qualify for the other programs, or to persons who are in need when eligibility for other types of assistance is uncertain. This program is paid for entirely from State funds.

Public Welfare Division (PWD) is the policy making unit for Public Welfare. These policies are carried out by State, District and Branch administrators with the assistance of Welfare staff. There are eight Districts and 36 Branches within 0regon's PWD. This report takes place in and is for the Multnomah County Public Welfare District.

\section{DESCRIPTION OF PROGRAM}

Medical Assistance (ORS Ch. 414) (7)

The Federally-aided Medical Assistance Program, sometimes called 
Medicaid or Title XIX, was implemented in Oregon on July 1, 1967.

It provides medical care for all recipients in the Federallyaided maintenance programs, $O A A, A B, A D$, and $A D C$, for persons who would be eligible for assistance in one of these programs but do not wish to receive it, for those who are patients in a medical institution and would be eligible to receive maintenance assistance if they left, for spouses whose needs are included in a Federally-aided maintenance grant, for those who are under 21 years of age, are in a foster family home or licensed child-caring institution or agency under a purchase of care agreement, and are ones for whom a public agency of this State is assuming financial responsibility, in whole or in part.

\section{Medical Transportation}

Medical transportation is a component of Oregon's Medical Assistance Program. Transportation to and from a source of medical care or between medical facilities is recognized by PWD as a necessary part of medical care. The rules and regulations covering this program are listed in the Appendix for reference.

\section{DESCRIPTION OF WEST BRANCH}

West Branch is located in the downtown area of Portland, Oregon. The area it services constitutes the core and fringe area of Portland and sweeps northward on the west side of the Willamette River, which is concentrated with industrial and commercial sites. Much of the area is characterized by low income people and low cost housing. It is a place where the aged, the disabled, the poor, and the indigent flock because 
of cheap housing and close proximity to shopping, medical clinics, skid row, etc. An estimate derived from the detoxification center data indicates that between four and five hundred Welfare recipients in the skid row are alcoholics. Therefore, to use this branch as a model or to compare it with any branch within the state system would be entirely unrealistic and unfair to those working in this branch.

Table I shows the makeup of West Branch population. These figures represent the estimate of unduplicated number of persons on assistance for 1973. It also depicts the number and percent of recipients within each program area compared with District and State.

TABLE I

WEST BRANCH PROGRAM POPULATION

COMPARED T0 DISTRICT

AND STATE

WEST

DISTRICT

STATE

No.

$\%$

No.

No.

$\%$

OAA

890

8.8

3,129

4.9

9,413

4.8

AB

55

.5

315

.5

954

.5

$\mathrm{AD}$

1,810

17.8

5,339

8.3

13,331

6.8

ADC

32.1

45,899

71.4

144,513

73.8

GA

$$
3,107
$$

30.6

6,916

10.8

18,870

9.6

TITLE XIX

$$
1,033
$$

10.2

2,601

4.1

8,634

4.4

TOTAL

$$
10,149 \quad 100.0
$$

64,199

100.0

195,715

99.9

As can be seen in the distribution, the West Branch population distribution differs somewhat from the District and the State population 
distributions in program areas. The OAA population is slightly higher for West than in the distribution for District and State, indicating a higher percentage of elderly people being served by this branch than on the average. Also within the $\mathrm{AD}$ and $\mathrm{GA}$ programs there is a larger population than normal. This is somewhat supportive of what was said earlier about the number of alcoholics and indigent population in the service area. This is because $A D$ and GA programs are highly male dominated programs which tend to be representative of the indigent population. Interesting also is that West Branch has the lowest ADC population in the District, although in number it is still the largest populated program in the branch.

Table II was derived by dividing the number of West Branch program populations into District program populations and District program population into State program populations to find out of what percentage the West Branch's program populations are of the District and the District is of the State.

TABLE II

\section{PERCENTAGE OF PROGRAM POPULATIONS WEST OF DISTRICT DISTRICT OF STATE}

$\begin{array}{lcc}\text { PROGRAM } & \text { WEST/DISTRICT } & \text { DISTRICT/STATE } \\ \text { OAA } & 28.4 & 33.2 \\ \mathrm{AB} & 17.5 & 33.0 \\ \mathrm{AD} & 33.9 & 40.0 \\ \text { ADC } & 7.1 & 31.7 \\ \text { TITLE XIX } & 39.7 & 29.0 \\ \text { TOTAL } & 15.8 & 32.8\end{array}$


As can be seen by this distribution, among five branches within the District, West serves $28.4 \%$ of the OAA population, $33.9 \%$ of the $A D$ population, $44.9 \%$ of the GA population, and $39.7 \%$ of TITLE XIX population, although the branch has only $15.8 \%$ of the District total Assistance population. 
REFERENCES

1. Oregon Public Welfare Division, Oregon's Public Welfare Programs and Services, PAM 9007A, Revised 1970, (Salem, Oregon), pp. 3.

2. State of Oregon, Legislation Relating to Public Welfare Division of the Department of Human Resources, 1971-1973, (Salem, Oregon), pp. $41-46$.

3. Ibid., pp. 35-38.

4. Ibid., pp. 38-40.

5. Ibid., pp. 67-78.

6. Ibid., pp. 28-30.

7. Ibid., pp. 47-53.

8. Oregon Public Welfare Division, Medical Assistance in Oregon, PAM 9006, Revised 1/73,. (Salem, Oregon), pp. 4-5. 


\section{DESCRIPTION OF THE PROBLEM}

Medical transportation presents some difficult problems to the Public Welfare Division. In other areas of medical care the provider who furnishes the professional services determines the medical need. For example, the physician arranges for admission to and discharge from the hospital, and prescribes specific drugs and medical supplies based on medical need; the dentist determines the dental needs of the patient; the optometrist prescribes the specific glasses required for adequate vision. However, medical transportation involving ambulances is often requested by the patient or someone not acquainted with the medical need. Furthermore, the medical profession and the providers of medical transportation are not in agreement on what transportation modality is appropriate at different levels of medical need. This problem is not as easily resolved as may first appear. For example, a nonemergent situation could become an emergent one during the process of transporting the patient. This issue will be discussed in a later chapter in relation to other components of the emergency care system.

Five other areas that appear problematic to the Public Welfare Division within the Medical Transportation Program are:

1. Cost.

2. Vagueness in policies and guidelines.

3. Lack of control in the delivery of service. 
4. Inadequate research data and information.

5. Inability to initiate change.

\section{I. $\operatorname{cosT}$}

Today, inflation is something that we are all concerned about. Its spiraling effect is almost daily news. The rising costs in medical transportation are no exception. The State Legislature allows as a "rule of thumb" a 5\% increase each year in program budgets. However, medical transportation has been increasing on the average of $15 \%$ each year. TABLE III shows available data since 1966 on how much this service has cost the tax payer, the number of users for all types of medical transportation, and the average cost for each user.

\section{TABLE III}

STATE MEDICAL TRANSPORTATION COSTS

$\begin{array}{lccc}\text { YEAR } & \text { USERS } & \text { AMOUNT } & \text { COST/USER } \\ 1966 & - & \$ 174,699 & - \\ 1967 & -- & 191,889 & - \\ 1968 & 15,800 & 242,895 & \$ 15.37 \\ 1969 & 17,085 & 274,344 & 16.06 \\ 1970 & 14,267 & 326,674 & 22.90 \\ 1971 & 14,437 & 378,298 & 26.20 \\ 1972 & 16,370 & 413,332 & 25.25 \\ 1973 & 19,824 & 512,660 & 25.86\end{array}$

As can be seen the total cost of medical transportation has almost tripled by increasing 193\% in the last eight years. Between 1968 and 
1972 the number of users increased by $25.4 \%$, the cost increased by $111 \%$, and the cost per user increased by 68\%. Also, between 1972 and 1973 the cost increase was $19 \%$, which exceeded the average yearly increase of $15 \%$. The higher increase in cost versus users is indicative of the present economic inflation trend.

TABLE IV has similar data for the Multnomah County District for the past three years. Information before 1971 could not be obtained. It also includes the percentage of users and costs that the District has of the Total State Medical Transportation Program.

TABLE IV

MULTNOMAH COUNTY DISTRICT
MEDICAL TRANSPORTATION
COST

$\begin{array}{lccccc} & \begin{array}{c}\text { USERS } \\ \text { IN } \\ \text { DISTRICT }\end{array} & \begin{array}{c}\text { PERCENT } \\ \text { OF } \\ \text { STATE* }\end{array} & \text { AMOUNT } & \begin{array}{c}\text { PERCENT } \\ \text { OF } \\ \text { STATE* }\end{array} & \text { COST/USER } \\ \text { YEAR } & 8,667 & 60.0 \% & \$ 222,372 & 58.8 \% & \$ 25.66 \\ 1971 & 10,483 & 64.0 & 251,449 & 60.8 & 23.99 \\ 1972 & 12,652 & 63.8 & 299,694 & 58.5 & 23.69 \\ 1973 & 12,8 & & & \end{array}$

*Percent of State figure.

Multnomah County District has approximately $63 \%$ of the users and $59 \%$ of the cost of the State medical transportation expense. The difference between the larger percentage of users and lower percentage of cost could be due to a combination of factors such as greater access to a wider variety of medical transportation modes (taxi, wheelchair car, stretcher cars, etc.) and/or, closer proximity to medical facilities. 
It is doubtful that the cost for the same modes of transportation is any cheaper in the Portland area than in any other area of the State.

A distribution of the number of persons eligible for medical assistance, and therefore, medical transportation, is representated in TABLE $\mathrm{V}$ for the years 1968 through 1972 .

\section{TABLE V}

TOTAL PERSONS ELIGIBLE FOR MEDICAL ASSISTANCE

$\begin{array}{lr}\text { YEAR } & \text { NUMBER } \\ 1968 & 73,908 \\ 1969 & 106,257 \\ 1970 & 126,006 \\ 1971 & 120,550 \\ 1972 & 113,781\end{array}$

The number of persons eligible for medical assistance has increased approximately 15\% per year for a total of $35 \%$ from 1968 to 1972 . However, the number of users for this service has only increased $3 \%$ for the same time period. Due to a large jump in transportation users between 1972 and 1973, there could be a margin of error; however, the overall totals seem to indicate that fewer people are utilizing this service.

A breakdown by mode of transportation produced by Public Welfare Division Statistics Department for the six month period beginning April 1, 1973 and ending September 30, 1973, showed the following percentages of expense per mode of transportation for the State Medical Transportation Program: 
TABLE VI

PERCENT OF EXPENSE PER MODE OF TRANSPORTATION

FOR STATE

\begin{tabular}{lr}
\multicolumn{1}{c}{ MODE } & PERCENT \\
AMBULANCES & $58.48 \%$ \\
TAXI & 15.48 \\
WHEELCHATR & 10.40 \\
BUS & 7.74 \\
GAS AND OIL & 4.99 \\
PLANE & .14 \\
TRAIN & .01 \\
OTHER & 2.76
\end{tabular}

As can be seen, ambulance expense far exceeds any other transportation modality.

A comparison was made with West Branch. TABLE VII includes the dollars expended for each mode covering the period from September 1 , 1972 to August 30, 1973. 
TABLE VII

\begin{tabular}{lrr}
\multicolumn{2}{c}{ BREAKDOWN OF WEST BRANCH EXPENSE PER } \\
\multicolumn{3}{c}{ MODE OF TRANSPORTATION } \\
MODE & AMOUNT & PERCENT \\
AMBULANCE & $\$ 53,994$ & $.55 .4 \%$ \\
TAXI & 17,210 & 17.6 \\
WHEELCHAIR & 13,656 & 14.0 \\
MISC. & 12,637 & 13.0 \\
& & 100.0 \\
TOTAL & $\$ 97,497$ &
\end{tabular}

Since West Branch reported a total transportation of $\$ 111,447$ during this same time period, it is uncertain about the exactness of these figures. There are many Welfare accounting processes with which this reasearcher is not familiar. However, the percentages give us some indication where West Branch is in comparison to the State for different transportation modalities. Ambulance transportation for West Branch $(55.4 \%)$ is slightly less than the State's percentage (58.48\%). This indicates that West Branch may not be overspending in this category in proportion to other transporting expenses. Taxi service is also less; however, wheelchair car is slightly more. It appears that the problem, if any, at this Branch is manifest throughout the Medical Transportation Program and not in one specific area. TABLE VIII gives a comparison of percentages of ambulance users to total transportation users. Also included is the transportation costs and the percentage of the total medical transportation costs for the years 1971, 1972, and 1973 for the State Welfare Division. This data was provided by the 
Statistics Department of Public Welfare Division.

\section{TABLE VIII}

$$
\begin{aligned}
& \text { AMBULANCE USERS AND COST FOR } \\
& \text { PUBLIC WELFARE DIVISION }
\end{aligned}
$$

$\begin{array}{cccccc}\text { YEAR } & \text { USERS } & \text { PERCENT } & \text { AMOUNT } & \text { PERCENT } & \text { COST/USER } \\ 1971 & 7,773 & 53.8 & \$ 294,897 & 78.0 & \$ 37.94 \\ 1972 & 6,385 & 39.0 & 253,216 & 61.3 & 39.66 \\ 1973 & 6,920 & 34.9 & 243,048 & 47.4 & 35.14\end{array}$

As can be seen here the number of ambulance users is going down and so is the cost for this transportation mode. The cost per user also seems to be diminishing, an apparent inconsistency with the next table. Since the first percent column reflects the percent of ambulance users in relationship to the total users of medical transportation, a higher use of alternative modes of transportation for medical reasons is indicated. The decrease in cost for ambulance transportation compared with the increase in cost for medical transportation also reflects this.

TABLE IX shows the increases in rate structures charged by Portland ambulance companies during the years 1966, 1970 and the recent increase in 1974. By flag drop is meant the basic charge for transporting an individual by ambulance without including charges for milage and special charges. 
TABLE IX

AMBULANCE RATES

YEAR

1966

1970

1974
FLAG DROP

$\$ 26.00$

35.00

50.00
CHARGE/MILE

$\$ 1.00$

1.00

2.00

This is almost a $100 \%$ increase in eight years. The recent increase will undoubtedly put a great strain on Public Welfare's budget for this program.

\section{Summary.}

The cost for Medical Transportation has almost tripled in the past eight years. Recent increases in rate structures and users of medical transportation will undoubtedly create a greater strain on Public Welfare Division funding processes for medical transportation. Multnomah County District has $63 \%$ of the users and $59 \%$ of the State's cost for medical transportation, which is a reflection of their responsibility to insure efficient and effective delivery of this social service.

Ambulance transportation comprises approximately $58 \%$ of medical transportation cost. Even though there is some indication that the cost and the number of users for this transportation modality is dropping, there needs to be a "watchful eye" on this because of the increased service rates which are estimated to be approximately $\$ 70$ per trip.

When looking at West Branch's total Medical Transportation Program in a cost percentage breakdown per transportation modality, we see 
a total medical transportation problem. There does not seem to be any particular mode that is causing the high cost for this service at this Branch.

\section{VAGUENESS IN THE PROGRAM POLICIES AND GUIDELINES}

Funds available to the Division of Public Welfare for all areas of medical care are very limited. Public Welfare administrators are given the responsibility of distributing those funds based on medical need. However, transportation poses an unusual situation.' With each new case needing medical transportation, it must be decided whether the medical need requires an ambulance or whether a servi-car or taxi would be adequate. Who makes this decision and when? The present policies and guidelines appear vague and inadequate in describing the priority of services to be rendered, the limitations, and the boundaries of the Program's system.

One indicator that supports this problem issue is the variety of ways different branches interpret the rules and guidelines (see APPENDIX for reproduction of rules and guidelines). For example, interviews with staff members of different branches throughout Multnomah County District indicated some branches appeared to have clearer interpretations of the policies and guidelines than others. Further, in an interview with an ambulance operator, mention was made about his desiring prior authorization for Welfare recipients. He said this was for his protection, especially in transporting Welfare recipients from Clackamas County. He claimed that Clackamas County rejects invoices for obscure reasons and will not pay, whereas Multnomah County Branches are generally good in paying on most invoices. 
The point here is that rules, policies and guidelines should be clear and succinct. They should explain purpose, priorities, limited resources, limitations of the service, and the boundaries that the social service delivery system operates within. These items should be written in a way that is easily interpreted by those who are delivering and providing the services. It is in this researcher's opinion that the present program does not do this. An analysis of the program will be given in a later chapter.

\section{LACK OF CONTROL IN THE DELIVERY OF SERVICE}

This area appears, in the opinion of this researcher, to be an outgrowth of archaic means of controlling. Methods used are through budget limitations, through post audits of ambulance services already rendered, and through attempting to use prior authorization as a control. Some of these methods may still be appropriate, but the targets or points to which they are applied may not be appropriate. For example, if a Welfare recipient had a heart attack and had to get prior authorization to obtain an ambulance, he probably would be dead by the time he reached the hospital. This is easy to understand and does not imply that it is Welfare policy. The point here is that there is a priority of medical needs. Some require immediate medical attention and some do not. It is identifying those situations that require immediate medical attention that is difficult. Here is a definition that may be helpful. The Funk and Wagnall's Standard College Dictionary defines an emergency as, "A sudden and unexpected turn of events calling for inmediate actior". The variables within this definition say that it is sudden and unexpected; 
therefore, prior planning or authorization cannot take place; and that it calls for immediate action, meaning time is of the essence. Ambu-. lances are equipped to handle this type of situation with emergency equipment, red lights, and sirens. Their function is to deliver a patient to. an emergency medical unit capable of handling the medical needs of the person immediately.

It was surprising to this researcher that emergent situations were defined by many others as including other situations and that ambulances were being used for other functions. Wheelchair and stretcher cars have almost the same equipment, however, they don't have red lights and sirens. These modalities are clearly for non-emergent situations and should have prior authorization.

The issue is not as simple as this when one gets into perceived needs of those requesting medical transportation and a secondary medical condition becoming a primary emergent one while transporting a patient, about which there is no data. However, it is clear that there is a priority of medical needs with a hierarchy of transportation modalities. Welfare should make this clear in policy and establish the boundary or limitation in delivering medical transportation service. If there are budget limitations, then it only makes sense to limit and provide the services that are on the top of the hierarchy of medical needs. This would be the first approach to control.

Another factor would be cost for services. To this researcher's knowledge there has never been an audit or cost analysis done on the ambulance companies in 0regon. However, there is a wide variation in charges. It would seem to make sense to find out what is a fair charge before taking the initiative of setting an arbitrary rate. This would 
be another control point that would, by the way, be within present policy.

The third factor includes one of the objectives of this report. That is to come up with variables that would be valid key indicators in identifying the extent of medical need in relationship to ambulance service. For example, are hospitals admissions a good and valid key indicator of the need for ambulance transportation? Does a transfer patient, a patient being transferred from one hospital to another or from a hospital to a nursing home or home, need an ambulance? These items will be discussed in a later chapter.

Control could be initiated in many different ways. However, the concern here is finding a limited control system that will still enable emergency medical care system to function smoothly. Possibly one of the best methods might be to educate. This will also be discussed later.

\section{INADEQUATE RESEARCH DATA AND INFORMATION}

The primary objective of this report is to provide research and information for a change proposal. The information from Public Welfare's information and data resources and the Portland community on the medical transportation was scanty and hard to come by; however, what was available and pulled together within the Welfare system and the larger emergency care system, representatives and constituencies should provide a basis for a change proposal.

\section{INABILITY TO INITIATE CHANGE}

The inability to initiate change has been due to two major factors, in this researcher's opinion. The first has been a lack of adequate 
research and data to initiate a change proposal. The second has been a failure to take the larger system into consideration makn a change proposal. The interferences and resistances to change are manifested not only in a sub-system funding a service, but in a larger system made up of emergency care components, local and state governments and agencies, medical and ambulance associations, the public, and the Welfare recipients who require this service, their representatives and constituencies. To reflect back on one incident that enlightens this problem, a study was done in 1970 by the Multnomah County Public Welfare District on ambulance transportation. (1) The primary emphasis of the study was to reveal and re-examine the practices relative to the use of ambulances and to see where program changes could be made that would assist in coming closer to the allotment of funds for medical transportation.

The focus of the study examined who was authorizing and referring medical transportation. Four major areas were identified:

1. County Physicians Office authorizing ambulances

2. Police emergency authorizing ambulances.

3. Nursing homes, homes for the aged, and hospitals authorizing ambulances.

4. Staff prior authorized ambulances.

It was felt that item four, Welfare authorized ambulances, contributed the smallest share of ambulance costs, so an in depth analysis was not done. A recap on the conclusions in the other three areas follow:

County Physician's Office Authorizations.

It was felt that the nature of the requests for ambulance service 
were such that relatively little change could be made at that time. However, the modification in reporting the situation by the County Physician's office could produce some use in alternate arrangements for the transportation of clients.

\section{Police Emergency.}

A review of the use of ambulances to transport patients to the Multnomah County Hospital and private hospitals revealed that: (1) Less than one-half of the patients were admitted to the Multnomah Counth Hospital. (2) Twenty-eight of the sixty-six patients sampled either made their own arrangements for return, or were sent by cab or bus, or the hospital did not know how they were returned home. This constituted $84 \%$ of the 33 cases not admitted to the hospital and raised a very serious question about the use of ambulances to deliver patients to the hospital. (3) For private hospitals the situation was similar, however, a much larger proportion of the patients were admitted to the hospitals. Out of 33 patients, 25 were admitted. This represented $75 \%$ of the patients transported to private hospitals who were admitted as contrasted to $47 \%$ of the patients carried to the Multnomah County Hospital. (4) It was reported that the police in their judgement call an ambulance to meet emergencies they are confronted with. The appropriate use of ambulances by the police was not in question. However, it was felt that their protection of the public and taking care of the need is a cost associated with the concept of protection of the public and should be borne by the appropriate city or county service. Also, the latitude of the police in deciding whether an ambulance is necessary must be preserved. However, 
the cost for the patients who are not admitted to the hospital and who are later determined as Public Welfare recipients must be borne by the City of County within the scope of protection of the public. Therefore, it was thought Public Welfare must pay only those ambulance costs where a patient was admitted to the hospital.

\section{Nursing Home Ambulances.}

It was felt necessary that Public Welfare require the nursing home or the persons ordering the ambulance to secure authorization prior to ordering the ambulance, if at all possible. If the need for the ambulance was determined during non-working hours, then the person requesting the ambulance must submit a request within the next working day. It was recommended that all ambulances be authorized on this basis for patients who are in nursing homes.

This study initiated several policy change proposals. The ones that I could identify were: (1) Not paying for transfers between hospitals. (2) Not paying for police referrals where the patient was not hospitalized. (3) A $\$ 37$ flat or maximum rate. (4) Prior authorization on all nursing home referrals. (5) A special form to be filled by the County Physicians Office for determining eligibility.

The reception to these change proposals was quite unfavorable. First, within the Welfare system the Medical Director took a position against several of these proposals. In a letter to the District Manager for Multnomah County Public Welfare he addressed three of these change proposals: transfers, rates and admissions. The following is a quotation from his letter: 
If a physician orders or arrangements are made to transfer a patient between hospitals we have no alternative but to accept the case. Medicare transportation is limited, but they cover transportation between medical facilities. Situations could give grounds for a turndown; i.e., transfer for convenience of the patient, doctor, or hospital, etc. To deny any and all transfers is beyond policy.

If a need exists for transporting the patient to the hospital, we cannot arbitrarily deny responsibility because he was not hospitalized. "Need" is the key to the situation. The matter of hospitalization is one of the important elements of need. The circumstances, etc., are equally important.

Under Rule Five of the guide, a carrier can by agreement with the County charge Welfare at rates less than charged the general public. This rule does not state that Welfare can arbitrarily force the reduced rate. (2)

During this same time period the District Manager for Public Welfare met with City and County government people to discuss ambulance payments and proposed that Welfare pay for only those ambulance trips which resulted in hospitalization. City and County officials felt that this was inappropriate and protested what they saw as transferring an obligation from Public Welfare to the County.

The response from the County Physician's Office was:

I would anticipate some troubles if an ambulance was dispatched in a given case and subsequently Welfare refused to pay on the strength of the information obtained from the form. The person summoning the ambulance may not have as complete information as is available when the form is completed and must make his judgement based upon the information available at that time. It would be unfair to require that the County pick up the tab on such cases when the decision has to be made on the best interest of the patient at the moment that the ambulance is summoned. In other words, a post audit to determine Welfare eligibility for ambulance reimbursement appears to me to be unfair in that it cannot possibly reflect the conditions under which the original judgement is made to summon the ambulance. (3) 
The response from medical transportation providers was mixed. Two ambulance companies refused and suggested Public Welfare consider purchasing services from someone else or go to the Emergency Board for more funds. On the proposal for a $20 \%$ budget reduction for taxi service, Radio and Broadway $\mathrm{Cab}$ refused on the basis that the fees were inadequate without any reduction. However, Rose City Cab Company readily accepted the $20 \%$ discount. Two organizations, Servi-car and Care Car reduced their fees 20\%. (4) The Portland Ambulance Association hired an attorney who refused the rate reductions, and wrote to the Governor of Oregon. These resistances and interferences to change proposals indicate the complexity and impact a change proposal will have in the political and larger system. Great care is needed in making any change proposals in estimating the political, social, and economic consequences. 
REFERENCES

1. John Burch, Ambulance Transportation for Multnomah County Public Welfare, Mimeographed, (Portland, Oregon: August 24, 1970).

2. D. E. Domke, M.D., Medical Director, Public Welfare Division, letter to Gordon Gilbertson, District Manager, Multnomah County Public Welfare, unpublished September 30, 1970, (in possessian of Multnomah County Public Welfare).

3. John H. Donnelly, M.D., M.P.H., Multnomah County Health Officer, letter to Gordon Gilbertson, District Manager, Multnomah County Public Welfare, unpublished August 18, 1970, (in possession of Muotnomah County Public Welfare).

4. James Cunneen, Assistant Administrator for Business Services, Multnomah County Public Welfare, Budget and Expenditure Data, unpublished month report, August 1970, (in possession of Multnomah County Public Welfare). 
CHAPTER III

\section{EMERGENCY HEALTH SERVICES}

Since the passage of the Medicare Law in 1965, Public Welfare has been an important resource for the needy in providing funds for primary health services. Emergency health services are an important component in the delivery of primary health services, and ambulance transportation is a primary component in the delivery of emergency health services. A study of ambulances or of Public Welfare policy in a vacuum could not, however, provide a good conceptualization of the problems or a means in which policy change can be based. 0ther components in interaction are just as important to consider. This chapter will focus primarily on what has been happening in Portland over the past few years, indicating trends, and identifying the various major components of the emergency health system.

\section{AMBULANCE COMPANIES}

Ambulance service in the City of Portland is provided principally by three privately owned companies; AA Ambulance, Buck Ambulance, and American Ambulance. These operate under a variety of business names, which largely accounts for the much larger number of ambulance service listings in the Portland telephone directory. The three ambulance companies together operate approximately 20 ambulances. A special city license is required for the operation of an ambulance service within the city, however, the city does not grant franchises to ambulance operators 
in that sense. They do have a city police dispatch system in which certain ambulance companies are assigned to cover certain areas within the city. The City Health Department inspects ambulances and equipment annually. Ambulance rates are not fixed by any public agency, although the city does require that the rates a company is charging be posted in the ambulance, and all ambulances are equipped with meters.

A typically equipped ambulance carries oxygen, resuscitation equipment and standard first aid equipment including splints, bandages, sponges, and similar items. Drugs are not carried by ambulances because it is illegal to do so.

The procedure at the scene and movement to the hospital is that upon arriving at the scene of the accident, the ambulance driver and attendent will render such first aid as may seem to be appropriate. If the patient is conscious, he will be asked to name the hospital to which he wishes to be taken, and he will be taken there. If the patient does not prefer a particular hospital, he will be asked the name of his family physician. The ambulance attendant will then relay the physician's name to his dispatcher who will advise him of which hospital staff the physician is a member. The ambulance dispatcher keeps a list of all the physicians in the city and the hospitals at which each practices. Patients who appear to be indigent and whose condition does not require their delivery to the nearest hospital will be taken to the Multnomah County Hospital. If the patient is not able to communicate, or, if he has an injury or condition which appears to require immediate care to preserve his life, he will be taken to the nearest hospital. The patient is the responsibility of the ambulance company until received at the hospital. 
It might be noted some of the above procedure could be helpful to Public Welfare, especially when identifying and obtaining directions on where the patient is to be taken. Public Welfare Policy states that a patient is to be taken to the nearest hospital. Using the ambulance dispatcher to identify a Welfare patient may be an important variable in determining the disposition.

Ambulance company operators are proud of their service and feel that their services are given in excellency. Most of these companies sponsor their drivers in advanced first aid course. Almost all drivers have now gone through the Fmergency Medical Training (EMT) course which is a sixteen-week course offered through Portland Community College. They feel also that by providing alternative modalities of medical transportation through stretcher car and wheelchair car services they have added to the dimension of medical transportation services.

Ambulance company operators feel that many of the problems of delivering efficient and effective services lie in existing case laws. Since they are bound by contract when arriving at the scene they are bound and obligated to deliver the service requested. However, they feel a person is in a disoriented state after having had an accident and his judgement of where he wants to be taken is not always appropriate.

The Good Samaritan Law, which is still in effect in Oregon's statues, states that a person giving treatment to an injured, stricken, or sick person may be liable for mistreatment. In 1971, SB 112. attempted to amend Oregon's Good Samaritan Law to provide immunity for acts or omissions of any person, regardless of whether or not they are medically licensed in the State of Oregon. All persons rendering emergency medical assistance 
would be subject to a standard of reasonable care under similar circumstances. This amendment would have provided immunity to emergency medical technicians for the important tasks that they are currently performing but for which they are presently liable. SB 112 did not get out of the Judiciary Committee in the 1971 legislation, nor has it appeared since. It was the consensus of the Judiciary Committee that the amendment did not change existing law. The advantage of having the present Good Samaritan Law amended is that it would provide statutory protection to the emergency medical technician in the event that existing case law is over-ruled by any given case. It would allow for strict interpretation of the statute by judges, which further protects the emergency medical technician from non-meritorious claims, and it would give the medical technician more discretion at the scene within his best judgement. (1)

Many ambulance technicians believe they can assess a person's medical condition quite accurately. For example, a big problem is epileptics. Most people, not knowing what a seizure is about, will call for an ambulance. The technician will assess the situation accurrately and then transport the patient to the hospital because he is required to do so. Before or after arriving at the hospital, the seizure will be over and the person will undoubtedly walk away. Also, there are what ambulance operators term "chronic repeaters". They know these people well because they transport them frequently. They also know that these people don't need ambulance transportation, nor do they need to be taken to the hospital. One operator confessed, however, that in one case they didn't respond until it was too late on one known "chronic repeater". 
Ambulance operators feel that Welfare is paying for unnecessary service. They feel that some Welfare recipients will call an ambulance because they don't have cab fare. Under present law a cab driver can take a person to jail if they don't have the fare, but ambulance drivers don't have the same sanction. They also feel that some recipients will wait until after the Welfare office closes to request an ambulance, thus avoiding the task of obtaining prior authorization.

Another problem area identified by ambulance operators was transfers. There was a question of why Welfare recipients are transferred from hospital to hospital after the first hospital found out the person was on Welfare. Another area of concern was the hospital to nursing home transfers. One ambulance driver claimed that $75 \%$ of ambulance trips were for taxi service and that only $25 \%$ were true emergencies.

It was suggested by one ambulance operator that Welfare should have a 24 hour switchboard with some kind of "tickler system" that would identify Welfare recipients and "chronic repeaters". This would enable ambulance operators to use an alternate system of some kind in handling these cases. The feasibility of this is uncertain and this researcher would suggest that this area be investigated for feasibility, utility and efficiency.

\section{The Portland City Club Report}

In 1966 the Portland City Club came out with a report assessing the quality of service given by the emergency medical care system. It was determined that problem areas in ambulance service were high in personnel turnover and had minimum requirements for training of ambulance 
technicians. At that time, training amounted to a Red Cross first aid card which was required by the County Health Officer, to be acquired within 90. days after receiving a permit to operate as a driver or attendant. All ambulance technicians were required to be registered with the County Health Officer. It was felt by the committee who prepared this report that improvement was needed in upgrading the skill and knowledge levels of ambulance technicians and that the high turnover rates was in contrast to this objective.

The Portland City Club felt that ambulances were well equipped but that the vehicles were designed more to conform to the accepted concept of appearance rather than for utility as emergency vehicles. ${ }^{(2)}$ Consideration was also given to the desirability of having a physician ride in the ambulance on all emergency calls. The committee did not feel that this was necessary.

The use of proper first aid techniques will be all that is possible until the patient is delivered to the hospital. It is at the hospital, where full equipment and highly trained personnel are available to work with the physician and surgeon under optimum conditions, that the principal treatment of the patient should take place.(3)

Also noted by the committee was that the majority of ambulance calls were not of emergency nature. "Witnesses before your committee estimate that only about twenty percent of the trips are for emergencies." (4)

A follow-up study done in 1970 revealed that private ambulance companies had accomplished substantial improvements voluntarily. Wages had increased and employment turnover had declined. Most of the ambulance drivers had completed the EMT course, and many were taking advanced training courses offered through the Multnomah County Medical Society. 
Another important development had taken place. Plans had been developed to provide radio communications between the hospitals and ambulances. This was considered a most important area of improvement in emergency services.

A facility which allows a well trained first aid attendant to alert the hospital to the patient's condition and needs before the patient's arrival saves precious time. (5)

In summary, the Portland City Club report indicated that the ambulance companies in Portland were providing a satisfactory service at a fair cost and that it was by no means either necessary or desirable to have a municipally owned, operated, or subsidized ambulance service because the present system is able to provide a service more economically

\section{HOSPITAL EMERGENCY TREATMENT UNITS}

In preceding years, increasing population in the metropolitan area has created greater demands for emergency services. The increase in volume has, however, dramatically exceeded the population growth. "Statistically, one out of every four or five persons in the Portland Metropolitan area will receive attention in a hospital. emergency room during a twelve month period." $(7)$

Increases in utilization of emergency services for what are termed nonemergent problems have caused hospitals to feel that there is a continuing need to educate citizens to alternatives and less expensive forms of medical treatment than is available in the emergency service departments. One of the most difficult problems the hospitals face is 
coping with the high cost of administering an emergeney service. Much of the cost incurred is in the nature of standby cost. Hospitals can build the standby costs into the rate structure for emergency services or take all or a portion of the standby cost and somehow work it into the rate structure of other parts of the hospital. The latter approach does not seem equitable to the inpatient who has not utilized the emergency service department.

The Portland City Club's report also included hospital emergency treatment units. They stated:

The Public is progressively relying more upon the hospital emergency facilities for the provision of medical care. Traditionally, many of these problems would have been reserved for a later visit to the family physician's office, but more and more it is proving convenient for the patient to present himself at the hospital emergency room where no appointment is needed and an evening visit does not interfere with the patient's daily routine. This tendency has been encouraged by the fact that medical insurance frequently covers only care given in a hospital and not similar care provided in a physician's office. The experience of most Portland hospitals over the last few years shows a 20 percent increase in volume of visits to the emergency facilities each succeeding year. (8)

The recommendation that the Portland City Club gave was that the public should be informed of the problem of overuse of emergency facilities and be requested to restrict their use of them to those problems that are genuine emergencies.

The use of the emergency facilities purely for the convenience of the patient is to be condemned. Medical and hospital insurance should be so written that emergency care given in a physician's office is covered in a manner similar to that provided in a hospital emergency unit. (9) 


\section{Comprehensive Health Planning Association Report}

In 1971 The Comprehensive Health Planning Association produced a report on the emergency medical care systems for Clackamas, Multnomah, and Washington Counties. This report stated that less than half the cases seen in an emergency unit are true emergencies. "More than half are medical, pediatric and obstetric problems." ${ }^{(10)}$ It was claimed that emergency rooms are utilized when the private physician is not immediately available or during other than normal working hours. Also, that emergency rooms are a retreat for the lonely.

This report claimed that the reason for the use of the emergency department is one of convenience, not only from the patient's viewpoint but from the physician's. The inability of the patient to get a doctor's appointment during the day, or when a problem occurs or becomes acute at night, or on the weekend, many times results in the patient's decision to come to an emergency department. Similarly, the physician, being unable to accept another patient into his schedule, will send the patient to the emergency department for examination and treatment with follow-up care at the physician's office several days or a week later. Additionally, the physician many times feels the need to use the backup diagnostic services of a general hospital to determine the course of treatment.

The Comprehensive Health Planning Association's position and recommendations were that emergency service is truly a community type of service that is provided to the community in somewhat the same fashion as fire and police protection. To this effect the report stated: 
One obvious difference between the services, of course, is the way in which the service is funded. If we had to pay for the cost of police protection or fire protection on the basis of a charge per call, many of us would find it financially quite impossible to call upon the police department or fire department.... Increasingly we are saying that health care in this country. is a right rather than a privilege, but the means for financing the service continues to be within the framework established when the prevailing philosophy was that health care is a privilege. (12)

Their recommendation was to avoid misuse of emergency facilities by providing outpatient facilities elsewhere within the hospital or the community for the care of the patients who present themselves at hospital emergency rooms because of lack of access to, and availability to, other medical facilities.

\section{POLICE}

Police have a defined responsibility to respond to calls for ambulances in cases which are criminal in nature, but find for some reason that they have assumed the same responsibility in civil cases as well. Bell Telephone will 95\% of the time refer the caller to the police dispatcher, but should instead call ambulances directly. Police feel loss of time is blamed on them because of their assumed role as an extension of their real role. The police feel that the solution might be to provide an ambulance dispatch system which is not bound by a district area like police are bound by. This would reduce some time that is lost.

Police dispatchers handle about 25 calls every 24 hours that justifịes employing a full time ambulance dispatcher. The police department has imposed a $\$ 600$ monthly fee on the ambulance companies for this service. Ambulance operators feel that this is morally wrong and have, 
therefore, never paid this service fee.

The County pays for about 15 of the 25 calls received every 24 hours. Up to September first of 1973 the rate was a flat no load fee of \$37. Under a new dispatch system which will be discussed shortly there is a $\$ 10$ response charge. The majority of calls fall in two areas: Ei ther the Northeast, or the Burnside area. It was recommended by police that it might be worthwhile to study the possibility of a city ambulance rescue car in one or both of these areas. The police feel that private ambulance companies are worried about drunks and indigents in these areas and rarely send an ambulance until a policeman is on the scene.

The police feel that the Detoxification Center is a problem because it does not have the facilities to handle the needs. Therefore, they put drunks in the civil hold at the Multnomah County jail if the person is disruptive, or if there is a charge against him. Police officers are trained in first aid, however, they rarely use it and rely heavily on ambulance technicians for this task. Their referrals are city cabs and ambulances. They have not been known to use intermediate medical transportation modalities.

A study done by the County Accounting Office in 1972 indicated that in many instances police officers called ambulances that were not needed. ${ }^{(13)}$ Since the county picks up the tab for indigent ambulance transportation runs referred by the police, the police have been pressured to make more appropriate ambulance referrals. 
Comprehensive Health Planning Association Report

The Comprehensive Health $\mathrm{Planning} \mathrm{Association} \mathrm{reported} \mathrm{a} \mathrm{problem} \mathrm{in}$ ambulance response time. They noted that ambulances did not respond until a police officer had requested an ambulance. It was felt this was a safeguard by the ambulance companies used to insure payment from the County for indigent people.

Under the old system, the police dispatcher would dispatch a police officer to the scene of the emergency. After the police officer determined the medical need, he would then radio for an ambulance. Once the request was logged in by the police officer, the County would pay the flat $\$ 39$ uncollectible no load fee if the bill was not paid within 30 days. The committee felt that this was unjustified and stated: "Money seems more important than the best emergency medical service possible". (14) The report also recommended the following"

Because of advances in medical technology, because ambulances are no longer of the "scoop and carry" variety and because considerable assistance is provided at the scene, we must draw a finer line between life and death. It is this advancement in life saving potential which encourages changes in the emergency response systems. (15)

Mayor's Policy Statement

The police dispatch system has been controversial for some time. A study done by Doug Capps for the Mayor's Office came out with a policy statement by the Mayor on this issue. This policy statement on emergency ambulance care went into effect September 1, 1973. The statement reads: (16)

1. Eliminating the prior dispatch of policemen, on most ambulance requests received by the radio division. 
2. Redistricting the city for better coverage of all areas.

3. Establishing, by ordinance, standards in equipment and personnel training as a prerequisite to an ambulance company being assigned a dispatch district.

4. Changing the reimbursement system from a $\$ 39$ uncollectible no load rate to an across the board $\$ 10$ response fee for all district calls.

The report claimed that time is saved by dispatching police and ambulance simultaneously. On those cases requiring police attention (i.e. accidents, shootings, assault, etc.) an ambulance is standing by to transport the injured without a delay in time. By dispatching only ambulances on medical situations, the new procedure eliminates police involvement on pure illness calls and frees the police officer to do police work. The study indicated that there would be an increase of ambulance runs of about five to ten percent, although it was felt that the reduction of charge would offset any additional cost for the service. The following quote was taken from the Oregon Journal:

Multnomah County Medical Society, doctors and ambulance companies agree that resulting delays in getting an iambulance to an emergency site can and probably do result in loss of life. (17)

Item three did not become a city ordinance, however, HB1227 which covers standards in equipment and personnel training, passed the State Legislature last year and will become effective July 1, 1974. The Mayor's report stated:

Without these standards, the assignment of a dispatch district can never be done on a rational and equitable basis. The city opens itself up to charges of favoritism and political pressure under the current assignment method. The only solution is to adopt standards, which if met will certify companies before they are permitted to participate in district calls. (18) 
In this researcher's opinion the support that ambulance companies have given on this issue has been to their own economic advantage, although it does also protect the community. By imposing strict standards and regulations, the government acts as a buffering system in keeping new competition from moving in. New companies have always been threatening to the old established ambulance companies. When American Ambulance started business about three or four years ago, they had some difficulty in being hooked into the police dispatch system until recently. The question arises if there really was a need for this legislation since ambulance companies had in the past taken it on their own initiative to upgrade their service, equipment, and personnel. In this researcher's opinion, the issue was political and not strictly for the well being of the community.

\section{THE MEDICAL PROFESSION}

The medical profession has in the past, and most likely will continue to have in the future, the most profound impact on standards, guidelines and policies in medical transportation. It is for this reason that the position and perceptions of two representatives of this constituency are quoted here. The first is from Dr. Norman Logan representing the Multnomah County Medical Society:

The Multnomah County Medical Society has worked diligently for a number of years to improve the quality of all medical transportation in Multnomah County. We believe stricter regulations for all forms of medical transportation are needed rather than dilution of regulations by categorizing types of transportation. The transportation needs of emergency and non-emergency patients are not nearly as 
easily separated as they might first appear. What may first appear as non-emergent may easily become an emergency. Lack of equipment or properly trained personnel can put the patient in serious jeopardy if a complication should arise. Improper handling of a chronic orthopedic patient can seriously complicate the existing condition. Patients who have been in a recumbent position for any length of time are much more susceptible to airway obstructions and respiratory complications, particularly when excited or apprehensive. (19)

This letter clearly states the Multnomah County Medical Society's position, and is probably one reason for the lack of interest in this research project, since this research is promulgating the "dilution of regulations by categorizing types of transportation". There are still questions about the effect of categorizing medical transportation modalities because the above statements are not supported very well. For example, to what extent, if any, do non-emergent situations become emer:gent?

The second quote is from Walter A. Goss, M.D., Multnomah County Health Officer:

A recumbent individual who is incapacitated or whose mobility is seriously restricted by virtue of his physical ailment or deformation should probably be considered to be of an emergency nature.... Every individual has a right to select their own mode of transportation but when a vehicle is licensed by the city to transport people, who by nature of their handicaps are potential risks and might develop into a secondary problem, then it is prudent and in the best interest of Portland to maintain its present system. (20)

This researcher is in debate over the above definition of an emergency. However, this position reflects that of the County and City and should not be taken lightly. As Dr. Goss stated, there is a potential risk and this risk cannot be ignored. 


\section{THE PUBLIC}

In the Comprehensive Health Planning Association report it was stated that, "To the individual any complaint may become an emergency if he cannot locate his physician at the moment". (21) If an emergency does come up, the mode of transportation is generally stereotyped. If the patient is consciaus and ambulatory, a private vehicle is generally used and if the patient is unconscious or not ambulatory an ambulance is used This sterotype is apparent when one observes who is requesting intermediate modes of transportation. Generally, it is only those people within or familiar with the medical transportation systems in the area. This indicates the lack of awareness and knowledge about the emergency medical care and transportation systems.

The delivery of emergency services is complicated by the lack of adequate definition and the differences in interpretation and perceptions of what is an emergency. To obtain some insight into the problem, it is necessary to look at some of the reasons why people present themselves at the emergency department. There seems to be three basis categories of problems: (1) Life and death situations, (2) Immediate need situations and (3) general need situations. The most obvious reason the emergency department in a hospital and an ambulance transportation service is established is because of accident, injury or severe illnesses where immediate treatment to save life or limb is the primary objective. This transcends all systems of the delivery of health care without respect to financial coverage, family physicians, 
facilities, Welfare policy or choice of alternatives. The Comprehensive Health Planning Association report stated that this group represents the smallest percentage of the total number of emergency visits and is generally accepted for the use for which it was intended. The balance of emergency visits, the other two categories, may be combined, those in which there is a need for immediate relief of pain or bleeding, etc., and those which require examination and treatment but can be handied through one of several alternatives.

In terms of definition there seems to be a consensus among the providers of health care that the emergency does exist in fact in the mind of the person regardless of the problem. The person defines the emergency and decides where and when he will obtain the services he needs. Generally speaking, it is felt that the public has developed the attitude that an emergency department is a community health center where anyone may apply with any kind of complaint. What results then, and has occurred across the country, is a tremendous influx in patient visits to the emergency department.

\section{Education and Information}

The Comprehensive Health Planning Association also studied what kinds of educational efforts are made to make the public aware of emergency health services and accident prevention programs available in the area and to ascertain the awareness of the public about these programs. A survey was mailed to schools and school superintendents, city government officials, industry, hospitals, health departments 
and nursing homes. It addressed the question of existing emergency services accident prevention programs in the four counties as recipients of the questionnaire perceived them, or were directly aware of them. It also asked about educational materials available through these programs, the emergency facilities in the communities, and the personnel and their qualifications within the emergency care program.

The general findings were that there was a wide diversity of programs in this area. The most predominant public information programs are conducted by the police, fire departments and Red Cross. Some activities are carried out by the County Health departments and the Portland Council of Hospitals. The effectiveness of these programs and the extent of public awareness about them could not be determined.

Respondents claimed that a health edcuation effort that is usually ignored is teaching the public what services can best suit their needs for specific problems and how to make use of those services.

At least one-half of the patients who crowd the emergency rooms are not emergencies. Greater effort needs to be made to make the public more self-reliant or knowledgeable of intermediate health measures. (23)

The recommendation they gave was that there is a need to coordinate information and education efforts that are being made or to form a clearinghouse of information so greater effectiveness can be achieved and greater concentration can be placed on special problem areas.

Reporting, Dispatching and Coordinating Emergency Problems

Multnomah County has no coordinator for emergency problems. If one looks at the emergency pages in the front of the telephone book they find 
very little help as there are many listings for police, sheriff and fire departments. Under ambulance companies we read "see yellow pages". There is a lack of reporting facilities for the public. There are no phones on the freeways and no toll free lines for emergency situations There have been a number of proposals throughout the years but still no action has been taken to alleviate this problem.

The Comprehensive Health Planning Association recommended that informational sources should be centralized into a 24 hour central referral and informational number to which the public can turn for assistance.

This is not to imply that any emergency should be diagnosed over the phone by a layman operating such a service, however, through a central number, widely publicized by brochures distributed at places like grocery stores, beauty or barber shops, and other common places of gathering, the public will have one place to turn for information without having to check innumerable sources in the yellow pages or by guess. (25)

The committee also recommended that funds be provided through the Comprehensive Planning Association to assist the study that was being proposed by the Columbia Region Association of Governments on the Universal emergency number "911''. This concept was proposed by Pacific Northwest Bell Telephone many years ago and is in operation in some 150 communities within the United States The "911" system provides one number, that is 911 , to dial on the telephone for all emergencies. The issue Pacific Northwest Bell raised was that the response time to emergencies can be reduced by the availability of a single emergency number known to all residents. (26) 
The Mayor's report claimed that the "911" system is not feasible. Their findings were that although Pacific Northwest Bell has shown a willingness to cooperate in any alternative system of dispatching, there were some basic limitations. Space for district maps are limited at the operator:'s switchboard. The turnover rate of telephone operators is high, so training becomes a problem. In addition, handling an ambulance request requires a fair amount of sophistication (i.e. assessment of need, nature of emergency, etc.) which may be beyond an operator's time limits. Furthermore, there are questions of legal and financial responsibility for false alarms and "no load" responses, and for even distribution of calls to qualified ambulance operators in the area. (27)

It is in this researcher's opinion that the last part is truer than the first part of this argument. The fact that the "911" system already operates in 150 communities in the United States says something to its feasibility. Since this is a mobile society a universal system would only enhance a person's knowledge about the emergency health system in Portland upon moving here. High turnover of operators is no different from the high turnover problem that ambulance companies had a few years ago. If there is that much training and sophisitication required in an emergency situation, which there is, why not pay for those skills? Since the County and City would have to pick up the tab on this system, positions are understandable.

The ambulance companies have been working on a central dispatch system that would replace the present system. This system would take medical emergency calls out of police hands by providing a central num- 
ber for medical emergency calls. It is felt that the cost and complexity of such a move is too great, however, recent discussions have indicated that cost may be offset by personnel savings in each company, and that existing equipment might be utilized. Their problem was stated that coordinating six ambulance companies (AA, Buck, American, Appollo, Tualatin Valley and Care Car) was anticipated. In this researcher's opinion, the problem is more how the ambulance companies will collect from the County for indigent people without the police dispatcher logging the referral.

\section{DAVID P. HOOPER ALCOHOLIC RECOVERY CENTER}

One of the primary problems Welfare staff perceived in the Medical Transportation Program was the inebriate. Since "Skid Row" is in West Branch's service area, this issue was the target of initial research. Responses to letters written to the Welfare and Police Departments of San Bernardino, California; Indianapolis, Indiana; Columbus, Ohio; New Orleans, Louisiana; and Miami, Florida; did not indicate that these cities were doing anything more about this problem or had they thought of any innovative or creative ways of handling the inebriated other than what Portland is already doing. The tread appears to be toward a detoxification center.

The Detoxification staff at David P. Hooper Alcoholic Recovery Center has had difficulties with the Portland Police Department. This was because it took a long time for Police officers to change their techniques in handling the alcoholic or inebriated. (27) There have been 
many complaints about police brutality, and only through administrative pressures did police begin to conform to present policies of delivery of the inebriated to the Detoxification Center. The police claim now that the Detoxification Center doesn't have the intake capacity to handle more than one drunk at a time. This is true; there is only one intake room and any more than one drunk brought into the center has to wait in the reception room alone until the other is through in the intake room. Often the drunk will wander away and be picked up again, making an excessive burden on the police. The Detoxification Center staff and the police have not been on good terms, reflected in alternative strategies by police. One of them has been to send the inebriated by ambulance to the Multnomah County Hospital for minor injuries. However, the Detoxification Center has a full nursing staff and could handle the majority of these cases. Also, there is a doctor there from six to seven every evening.

Recently the Detoxification Center started the Rapid Outreach Police Intake System (ROPIS). Through funds provided through the city a station wagon was procured and a special staff was hired to go out and pick up inebriates. This began September 1, 1973. The results and impact of this new system are not known yet but it will surely help in alleviating some of Public Welfare, City, County and Police problems. 


\section{REFERENCES}

1. Comprehensive Health Planning Association for the Metropolitan Portland Area, Report on the Committee on Emergency Medical Care Systems in Clackamas, Columbia, Multnomah and Washington Counties, Mimeographed, (Portland, Oregon), p.44.

2. Douglas Capps, Mayor's Policy Statement on Emergency Ambulance Care, Mimeographed, (Portland, Oregon, September 29, 1973), p. 22.

3. Ibid., p. 44 .

4. Ibid., p. 42 .

5. Ibid., p. 24 .

6. Ibid., p. 45 .

7. Comprehensive Health Planning Report, p. ii.

8. Portland City Club, "Report on Emergency Care to the Injured and Stricken in the Portland Area", Portland City Club Bulletin, City Club of Portland, (Portland, Oregon, September 9, 1966), Vol. 47, No. 15, p. 46.

9. Ibid., p. 51 .

10. Comprehensive Health Planning Report, p. 2.

11. Ibid., p. 30 .

12. Ibid., p. 26 .

13. Multnomah County Government Accounting Office, Report on Police Dispatched Ambulances, unpublished, (Portland, Oregon, April 26, 1972).

14. Comprehensive Health Planning Report, p. 23.

15. Ibid., p. 2 .

16. Douglas Capps, p. 1 .

17. "Family Blames Ambulance System For Lost Life", Oregon Journal, 17 March 1973.

18. Douglas Capps, p. 5 . 
19. Norman Logan, M.D., Multnomah County Medical Society, letter to City of Portland, unpublished, in possession of Mayor's Office, Portland, Oregon.

20. Walter A. Goss, M.D., Multnomah County Health Officer, letter to City of Portland, unpublished, in possession of Mayor's Office, Portland, Oregon.

21. Comprehensive Health Planning Report, p. 23.

22. Ibid., p. 30 .

23. Ibid., p. 20 .

24. Ibid., p. 20 .

25. Ibid., p. 20 .

26. Ibid., p. 3 .

27. Office of PEPD, The First Step-David P. Hooper Alcoholic Recovery Center Follow-up Evaluation, (Portland, Oregon, June 25, 1973), pp. 39-40. 


\section{CHAPTER IV}

\section{WEST BRANCH STUDY}

This chapter contains data on the study at West Branch, Multnomah County Public Welfare, which was done by this researcher beginning the first week in November, 1973, and ending the last week of January, 1974. For a description of the characteristics of West Branch, the population sampled, and the methodology, please refer back to Chapter I.

\section{DEFINITION OF TERMS}

Some of the terms and expressions used in this study may be confusing to those not familiar with Public Welfare's Medical Transportation Program, or with the sampling methods of this study. Therefore, listed below are explanations and definitions:

Programs (please refer to Chapter I for program purposes and eligibility requirements)

0AA: 0ld Age Assistance.

ADC: Aid to Dependent Children

AB: Aid to the Blind.

AD: Aid to the Disabled.

GA: General Assistance.

\section{Origin-Destination}

Origin: Where the ambulance picked the patient up.

Destination: Where the patient was taken. 
Codes (Represents points of origin or destination.)

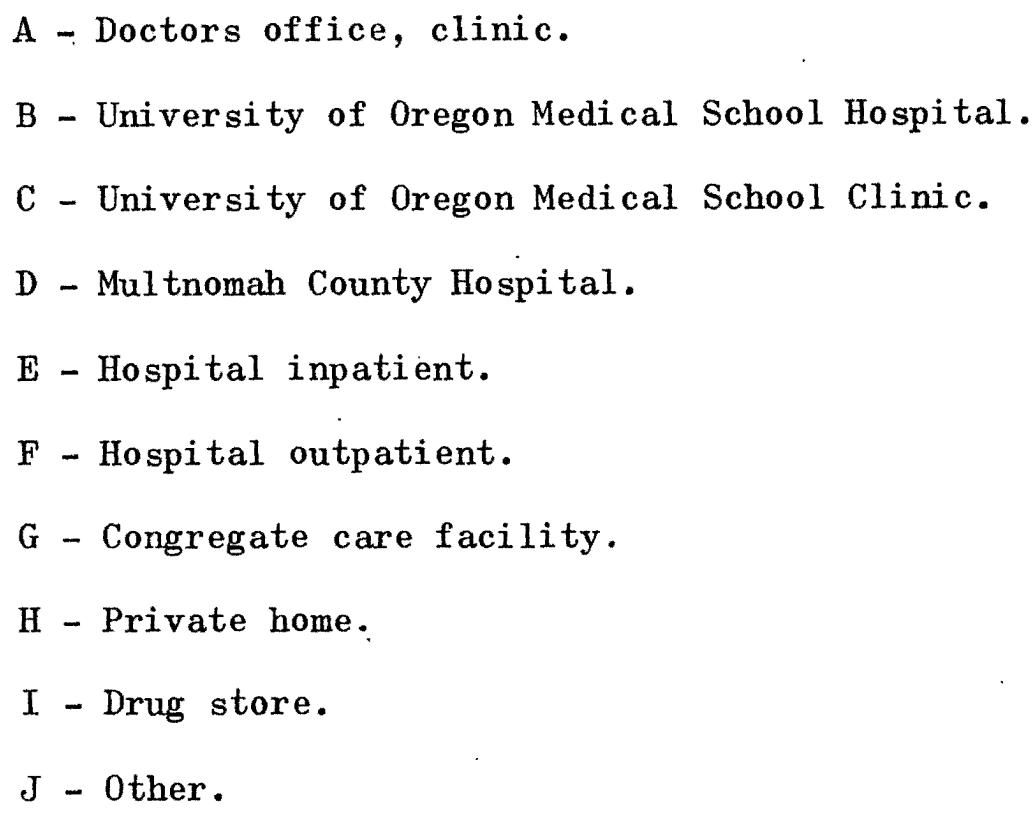

\section{Referrals}

Police: Police requested the ambulance.

Welfare: Welfare requested or authorized the request for ambul ance.

Private: $\quad$ Congregate care facility, the public, or Welfare recipient requested the ambulance.

County: County Physician's Office requested the ambulance.

Medical Transfer

Medical: The ambulance trip was for transporting a patient for medical treatment.

Transfer: The ambulance trip was for transporting a patient other than for medical treatment.

Admi ssions

Refers to whether the patient was admitted to a hospital as a bed patient or treated and released. 


\section{ORIGIN AND DESTINATION}

\section{Points of Origin and Destination}

TABLE $X$ is a cluster analysis of where the Welfare recipient was picked up and where he was taken, showing the number of sampled recipients at each point of origin, the destination and the percentages at each point to the total sample population. The $\mathrm{E} / \mathrm{F}$ point on the destination side is where it was not known if the destination was $E$ or $F$.

\section{TABLE X}

POINTS OF ORIGIN

AND DESTINATION

\section{Destination/Origin}

\begin{tabular}{|c|c|c|c|c|c|c|c|c|c|c|}
\hline & A & $\mathrm{B}$ & $\mathrm{D}$ & $\mathrm{E}$ & $\mathrm{F}$ & $\mathrm{G}$ & $\mathrm{H}$ & $\mathrm{J}$ & TOTAL & $\%$ \\
\hline$B$ & - & - & 1 & - & - & 2 & - & - & 3 & 2.2 \\
\hline $\mathrm{C}$ & - & - & - & - & - & - & 2 & - & 2 & 1.4 \\
\hline D & 1 & - & - & - & 1 & 17 & 29 & 28 & 76 & 54.7 \\
\hline $\mathrm{E}$ & - & - & 1 & - & - & 8 & 13 & - & 22 & 15.8 \\
\hline$\frac{E}{F}$ & - & - & - & - & - & 5 & 2 & 2 & 9 & 6.5 \\
\hline$F$ & - & - & - & - & - & - & - & 2 & 2 & 1.4 \\
\hline G & - & 1 & 15 & 4 & 1 & - & - & - & 21 & 15.1 \\
\hline $\mathrm{H}$ & - & 1 & 1 & - & - & 1 & - & - & 3 & 2.2 \\
\hline$J$ & - & - & - & - & - & - & 1 & - & 1 & 0.7 \\
\hline TOTAL & 1 & 2 & 18 & 4 & 2 & 33 & 47 & 32 & 139 & 100.0 \\
\hline$\%$ & 0.7 & 1.4 & 13.0 & 2.9 & 1.4 & 23.8 & 338 & 23.0 & - & 100.0 \\
\hline
\end{tabular}


The cluster analysis shows that most ambulance trapgortation occurs in the middle right side of the table.

As can be seen by the distribution, $53.3 \%$ of the recipients transported by ambulance were from a congregate care facility (17), home (29), or other (28) to the Multnomah County Hospital. Since Multnomah County Hospital is the major hospital serving the West Branch area, this would indicate that slightly over half of ambulances (54.7\%) are going to the nearest hospital. Another $23 \%$ went from congregate care facility, home, or other, to a hospital other than Multnomah County Hospital, which indicates that some patients are not being transported to the nearest hospital. Fourteen percent went from Multnomah County Hospital or other hospital to a congregate care facility. This means that one in every ten ambulance trips is for transfers from a hospital to a nursing home. Thirty eight and nine tenths percent of ambulance trips are from or to a congregate care facility. This indicates that over one third of all ambulance transportation trips are for people in a congregate care facility.

Point $J$ (other) represents a person being picked up from the street, a bar, or some other place which is not listed in the codes. Of some interest is that most of the ambulance trips from point $J$ originated in the skid row area. Since $23 \%$ of the cases originated from point $J$, this appears to indicate that a high proportion of ambulance trips originate in the skid row area in comparison to other parts of the city. 
Points of 0rigin and Destination Compared to Program.

TABLE XI shows the origin and destination of ambulance trips to the program the Welfare recipient is in, giving the totals of those ambulance trips that originated from a certain point and the totals of those ambulance trips that had a destination at a certain point.

TABLE XI

SOURCE AND DESTINATION

COMPARED WITH

PROGRAM

\begin{tabular}{|c|c|c|c|c|c|}
\hline OAA & $\mathrm{ADC}$ & $A B$ & $\mathrm{AD}$ & GA & TOTALS \\
\hline FROM & FROM & FROM & FROM TO & FROM & FROM \\
\hline
\end{tabular}

$\begin{array}{lrrrrrrrrrrrrrr}\mathrm{A} & 1 & - & - & - & - & - & - & - & - & - & 1 & - \\ \mathrm{B} & 1 & 2 & - & - & - & - & 1 & 1 & - & - & 2 & 3 \\ \mathrm{C} & - & - & - & - & - & - & - & 2 & - & - & - & 2 \\ \mathrm{D} & 13 & 19 & - & 5 & 1 & 1 & 4 & 39 & - & 12 & 18 & 76 \\ \mathrm{E} & 3 & 13 & - & 1 & - & - & 1 & 8 & - & - & 4 & 22 \\ \mathrm{E} / \mathrm{F} & 1 & 5 & - & - & - & - & 1 & 4 & - & 2 & 2 & 11 \\ \mathrm{G} & 21 & 14 & 1 & - & - & 1 & 10 & 6 & 1 & - & 33 & 21 \\ \mathrm{H} & 10 & 1 & 3 & - & 1 & - & 26 & 1 & 7 & 1 & 47 & 3 \\ \mathrm{~J} & 4 & - & 2 & - & - & - & 19 & 1 & 7 & - & 32 & 1\end{array}$

Sixty seven percent of ambulance trips from the Multnomah County Hospital or a congregate care facility are OAA program. This represents $63 \%$ of the total sampled $0 A A$ recipients.

Destinations for OAA program recipients are fairly evenly distributed among the Multnomah County Hospital (35\%), other hospitals (33\%), and 
congregate care facilities (26\%).

Eighty-three percent of the ADC program recipients (6 patients), went from home, or other, to the Multnomah County Hospital. The two AB recipients went from home to the Multnomah County Hospital and from the Multnomah County Hospital to a congregate care facility. There was an even distribution from home or other to the Multnomah County Hospital among GA recipients.

Seventy-three percent of the $A D$ recipients went from home or other to the Multnomah County Hospital $(63 \%)$, or other hospital (19\%), or a congregate care facility $(10 \%)$. Fifty-five percent of all those with an origin of home were $\mathrm{AD}$ recipients. Fifty-nine percent of all those from other were $A D$ recipients.

\section{USERS OF AMBULANCE TRANSPORTATION}

\section{Users of Ambulance in Each Program}

From the previous table the following data was derived showing the number of users within each program area and the percentage that each program is of the total sampled population in ambulance transportation. 
TABLE XII

$\begin{array}{lcc}\text { USERS OF AMBULANCES BY PROGRAM } & \\ \text { PROGRAM } & \text { NUMBER } & \text { PERCENT } \\ \text { OAA } & 54 & 38.9 \\ \text { AB } & 2 & 1.4 \\ \text { AD } & 62 & 44.6 \\ \text { ADC } & 6 & 4.3 \\ \text { GA } & 15 & 10.8 \\ \text { TOTAL } & 139 & 100.0\end{array}$

The data indicates the highest percentage of users is in the OAA program (38.9\%) and AD program (44.6\%). Referring back to TABLE I, in CHAPTER I, the reader can note that OAA represents $8.8 \%$ of West Branch's total recipient population and $\mathrm{AD}$ represents $17.8 \%$ of West Branch's total recipient population. This means that $83.5 \%$ of the users of ambulances come from $26.6 \%$ of the branch's total recipient population.

Age

Sickness and illness often increase with age, thus creating a greater demand for ambulance transportation and hospitalization. TABLE XIII shows the average and modal ages by program, in the sample. 
TABLE XIII

$\begin{array}{lrc}\text { AGE OF AMBULANCE USERS BY PROGRAM } \\ \text { PROGRAM } & \text { AVERAGE } & \text { MODE } \\ \text { OAA } & 78.8 & 70 \\ \text { ADC } & 20.0 & 16 \\ \text { AB } & 35.5 & - \\ \text { AD } & 51.6 & 55 \\ \text { GA } & 37.6 & 43 \\ \text { TOTAL/AVERAGE } & 59.7 & 55\end{array}$

It appears then that the programs with the highest percentage of ambulance users are also the programs with the oldest age groups.

IV. AMBULANCE REFERRALS

Referrals Compared with Origin and Destination

TABLE XIV shows who called for the ambulance and compares this with where the recipient was picked up and where he was taken. 
TABLE XIV

\begin{tabular}{cccccccc}
\multicolumn{8}{c}{ REFERRALS COMPARED WTTH } \\
\multicolumn{7}{c}{ ORIGIN AND DESTINATION } \\
POLICE & WELFARE & PRIVATE & COUNTY & , TOTAL \\
FROM TO & FROM TO & FROM & TO & FROM & TO & FROM & TO
\end{tabular}

$\begin{array}{lrrrrrrrrrr}\text { A } & - & - & - & - & - & - & 1 & - & 1 & - \\ \text { B } & - & - & 2 & 1 & - & 1 & - & 1 & 2 & 3 \\ \mathrm{C} & - & - & - & 1 & - & 1 & - & - & - & 2 \\ \mathrm{D} & - & 53 & - & 6 & 2 & 13 & 16 & 4 & 18 & 76 \\ \mathrm{E} & - & 6 & 4 & 7 & - & 9 & - & - & 4 & 22 \\ \mathrm{E} / \mathrm{F} & - & 4 & 1 & 1 & - & 6 & 1 & - & 2 & 11 \\ \mathrm{G} & 2 & - & 11 & 5 & 17 & - & 3 & 16 & 33 & 21 \\ \mathrm{H} & 32 & - & 6 & 2 & 9 & 1 & - & - & 47 & 3 \\ \text { J } & 29 & - & - & 1 & 3 & - & - & - & 32 & 1 \\ \text { TOTAL } & 62 & 63 & 24 & 24 & 31 & 31 & 21 & 21 & 139 & 139 \\ \% & 45.3 & 17.3 & 22.3 & 15.1 & 100\end{array}$

Ninety-seven percent of the police referrals were from home or other, and $84 \%$ had the destination of Multnomah County Hospital. This depicts that the type of referrals police make are those cases that take place in the home or in the street. The high percentage of ambulances going to the Multnomah County Hospital indicates that most police referrals are close in proximity to this hospital or that this is a standard procedure of the police. 
Seventy-one percent of the Welfare referrals were from home or a congregate care facility. Twenty-five percent of Welfare referrals had the destination of Multnomah County Hospital. A point of interest is that $33 \%$ of Welfare referrals had a destination of other hospitals. The question arises as to why Welfare staff is transporting recipients out of the area. Twenty-one percent of Welfare referrals had the destination of a congregate care facility. This means that one out of every five Welfare requested or authorized referrals are for transferring a recipient to a congregate care facility. The distribution of Welfare referrals is less concentrated than any other source of referral.

Fifty-five percent of private referrals had the origin of a congregate care facility. Over half of private referrals are by congregate care facility staff. Twenty-nine percent of private referrals were from home. Forty-two percent of private referrals had the destination of Multnomah County Hospital and $48 \%$ had the destination of other hospitals. Seventy-six percent of County referrals had the origin of Multnomah County Hospital and $76 \%$ of the recipients went to a congregate care facility. This indicates that most County referrals are for congregate care people. Nineteen percent of County referrals had an origin at a congregate care facility or other hospitals and had the destination of Multnomah County Hospital. The County referral system is critical as it partially explains the reason for transfers; that is, transfers are generally for congregate care Welfare recipients.

Police referrals account for $45.3 \%$ of all referrals. Because of the large police role in the referral system, one can understand why 
Welfare staff is concerned about how ambulance referrals are processed. It is apparent that the more one is in the eyes of others to observe and the more referrals made, the more mistakes can be observed if one has a lower than $100 \%$ accuracy. This often will obscure what is really the situation.

\section{Referrals Compared to Programs}

The next Table shows the types of referral in comparison to programs.

TABLE XV

NUMBER OF CASES BY REFERRAL SOURCE AND PROGRAM

POLICE WELFARE PRIVATE COUNTY TOTALS

$\begin{array}{lrrrrr}\text { OAA } & 8 & 15 & 16 & 15 & 54 \\ \mathrm{ADC} & 5 & - & 1 & - & 6 \\ \mathrm{AB} & 1 & - & - & 1 & 2 \\ \mathrm{AD} & 38 & 7 & 12 & 5 & 62 \\ \mathrm{GA} & 11 & 2 & 2 & - & 15 \\ \text { TOTAL } & 63 & 24 & 31 & 21 & 139\end{array}$

The police have the largest number of referrals (63). Sixtyeight percent of police referrals are for Welfare recipients within the $\mathrm{AD}$ and GA programs. Sixty-one percent are from the $\mathrm{AD}$ program alone which amounts to $27 \%$ of all referrals. The police referrals in the $\mathrm{AD}$ program therefore are an area of importance in ambulance transportation. 
Also, it is in this program that a large percentage of alcoholics residing in the skid row area are participating.

Welfare referrals are concentrated mostly in the OAA program. These are most likely requests from congregate care facilities for prior authorized ambulances. Half of the private referrals are also most likely congregate care facility ambulance requests which are not prior authorized by Welfare. Most of the county referrals are for OAA program recipients, which is again referrals for transfer of patients from hospital to congregate care facility.

Referrals Compared to the Reason for Ambulance Transportation

The reason for ambulance transportation was coded in two general areas. Either the ambulance was used for transporting a person for medical treatment which was categorized as "medical", or the ambulance was used for transporting a person for purposes other than for medical treatment, which was categorized as "transfer". TABLE XVI shows the referral source and whether the reason for transporting the person by ambulance was for medical or transfer reasons.

TABLE XVI

THE PERCENT OF MEDICAL AND TRANSFER CASES BY REFERRAL SOURCES

$\begin{array}{lll}\text { POLICE WELFARE } & \text { PRIVATE TOTNTY }\end{array}$

TRANSFER

20.8

6.5

76.2

$17 \cdot 3$

MEDICAL

98.4

79.2

93.5

23.8

82.7 
The table shows $17.3 \%$ are transfers and $82.7 \%$ are ambulance trips for medical reasons. Welfare and County referrals have most of the transfers. Police referrals are $98.4 \%$ of the time ambulance transportation for medical reasons. Private referrals are $93.5 \%$ of the time for medical reasons. However, County transferred $76.2 \%$ of their cases. By cross checking the reason for transporting by ambulance for each program, the following table was derived:

\section{TABLE XVII}

PERCENT OF CASES WITHIN EACH PROGRAM

$\begin{array}{lcccccr} & \text { OAA } & \mathrm{ADC} & \mathrm{AB} & \mathrm{AD} & \mathrm{GA} & \text { TOTAL } \\ \text { TRANSFER } & 27.8 & - & 50.0 & 11.3 & 6.7 & 17.3 \\ \text { MEDICAL } & 72.2 & 100.0 & 50.0 & 88.7 & 93.3 & 82.7\end{array}$

Since there were only two persons sampled in the $A B$ program, the percentages listed above might not be valid. However, approximately one in every four OAA program transportees is for transfer reasons. This most likely is because of their age and delicate condition. One hundred percent of the $A D C$ recipients were for medical reasons. The average age of OAA was 78.8 years, and the average age of $\mathrm{ADC}$ was 20 years.

\section{TEMPORAL BREAKDOWN FOR AMBULANCE TRANSPORTATION}

Requests For Ambulances During and After Office Hours

It was felt by many Welfare staff and other people in the'medical transportation service area that Welfare recipients, congregate care 
staff, and others were waiting until after Welfare office hours to request an ambulance, thus avoiding obtaining prior authorization for this service. Taking into consideration weekends and holidays, the following table was derived showing the number of cases by referral source that were requested during and after Welfare office hours at West Branch:

\section{TABLE XVIII}

\section{CASES REFERRED DURING AND AFTER}

OFFICE HOURS BY SOURCE

POLICE WELFARE PRIVATE COUNTY TOTAL

$\begin{array}{lrrrrr}\text { OFFICE HOURS } & 23 & 20 & 5 & 16 & 64 \\ \text { NON-OFFICE HOURS } & 40 & 4 & 26 & 5 & 75\end{array}$

There are more requests for ambulances during non-office hours than during office hours. The picture changes slightly, however, when one considers there is a normal work week of 40 hours which leaves 128 hours during the week that Welfare offices are closed. This means that there are 1.6 referrals per hour during office hours and 1.7 referrals per hour during non-office hours.

Of the 64 cases ( $46 \%$ of the referrals) transported during office hours, $36 \%$ of them were police referrals, $31 \%$ Welfare referrals, $8 \%$ private referrals and $25 \%$ County referrals. Prior-authorized or Welfare referrals make up approximately one-third of all ambulance referrals during office hours.

Of the 75 cases ( $54 \%$ of the referrals) transported during nonoffice hours, $53 \%$ were police referrals, $5 \%$ Welfare referrals, $35 \%$ private 
referrals, and $7 \%$ County referrals. The higher proportion of police referrals during non-office hours probably indicates their higher involvement in the emergency transportation system during this time period. The higher proportion of Welfare referrals to private referrals during office hours indicates prior authorization is obtained.

During non-office hours private referrals are made without prior authorization. This does not prove that they are waiting until after Welfare hours, but shows that during non-office hours the private referral system is most operative.

Time of Request For Ambulance

The following table shows the time that the services were delivered:

TABLE XIX

NUMBER OF CASES BY

TIME OF SERVICE

$\begin{array}{llr}9 \text { a.m. } & 1 \text { p.m. } & 46 \\ 1 \text { p.m. } & 5 \text { p.m. } & 32 \\ 5 \text { p.m. } & 9 \text { p.m. } & 24 \\ 9 \text { p.m. }-1 \text { a.m. } & 17 \\ 1 \text { a.m. } & 5 \text { a.m. } & 8 \\ 5 \text { a.m. } & 9 \text { a.m. } & 12\end{array}$

The highest proportion of ambulance trips are during the day (78 cases or 56\%) regardless of weekends and holidays. Fortymone cases or $29 \%$ went between 5 p.m. and 1 a.m., and 20 cases were transported between 1. a.m. and 9 a.m. 


\section{Seasonal Patterns}

Since the sample covered more than one year (see sampling process) the following table could be off to some degree; however, it does give some general idea as to the seasonal patterns of ambulance use. TABLE $X X$ gives the seasons in which the ambulances were used and compares them with programs.

TABLE XX

SEASONAL PATTERNS COMPARED

WITH PROGRAMS

PERCENT

$\begin{array}{lccccr}\text { PROGRAM } & \text { MODAL } & \text { WINTER } & \text { SPRING } & \text { SUMMER } & \text {. FALL } \\ & \text { MONTH } & & & & \\ \text { OAA } & \text { OCTOBER } & 18.5 & 9.3 & 38.9 & 33.3 \\ \text { ADC } & - & 16.7 & 16.7 & 50.0 & 16.7 \\ \text { AB } & - & - & 50.0 & 50.0 & - \\ \text { AD } & \text { JUNE } & 19.4 & 12.9 & 38.7 & 29.0 \\ \text { GA } & \text { MAY } & 13.3 & 33.3 & 33.3 & 20.0 \\ \text { AVERAGE } & \text { OCTOBER } & 18.0 & 14.4 & 38.8 & 28.8 \\ & \text { (JUNE \& JULY CLOSE) } & & & \end{array}$

As can be seen, the modal month varies by program and the largest overall usage is during the summer.

\section{REPEATS}

Repeats Compared with Referrals

From the sampled population a count was made on the number of 
times each person used an ambulance covering a period beginning approximately July 1, 1973, and ending December 31, 1974, approximately one and a half years. TABLE XXI shows the average number of times used by referral source.

TABLE XXI

AVERAGE NUMBER OF REPEATS

PER PERSON BY REFERRAL SOURCE

$\begin{array}{ll}\text { POLICE } & 5.0 \\ \text { WELFARE } & 2.7 \\ \text { PRIVATE } & 2.3 \\ \text { COUNTY } & 3.0\end{array}$

As is indicated, police are making more referrals for the same Welfare recipients than any other referral source; County runs second. This seems to be consistent with the age groupings that were discussed earlier and the general health of the populations from which they are making the referrals. Police make many ambulance referrals for the indigent population which is highly concentrated with alcoholics from the skid row area. Alcoholism contributes to many health problems that undoubtedly cause an above average need for medical treatment. Repeats Compared With Programs

To verify if the above claim may be true, a cross check was made by running the number of times each Welfare recipient used ambulance service and compared this with the programs they were in. The $A D$ program 
has the highest number of alcoholics and are second in age to 0AA.

TABLE XXII

REPEATS COMPARED WITH
PROGRAMS

$\begin{array}{cc}\text { PROGRAM } & \text { AVERAGE } \\ \text { OAA } & \text { TIMES USED } \\ \text { ADC } & 2.2 \\ \text { AB } & 1.3 \\ \text { AD } & 6.5 \\ \text { GA } & 5.3 \\ \end{array}$

The AB program recipients had the highest average in number of times an ambulance was used per person. Since there are only two samples within this program, there is some question whether this was true for the total population of $A B$ recipients. However, the number of times ambulances were used by the $\mathrm{AD}$ population. is 5.3, which corresponds closely with what was said about police referrals, indigents, and alcoholics.

The average number of times ambulances were used for all programs was 3.7 and the mode was 1 . The average number of times used each year is 2.5 per person in the sample.

VII. $\operatorname{cosT}$

TABLE XXIII shows the percentages of the sample populations within cost groupings by referral source. 
TABLE XXIII

COST PER TRIP

$\begin{array}{lccccc}\text { DOLLARS } & \text { POLICE } & \text { WELFARE } & \text { PRIVATE } & \text { COUNTY } & \text { TOTAL } \\ 45< & 15.9 & 20.8 & 3.2 & 4.8 & 12.2 \\ 45-50 & 23.8 & 33.3 & 16.1 & 38.1 & 25.9 \\ 50-55 & 33.3 & 16.7 & 25.8 & 19.0 & 26.6 \\ 55-60 & 22.2 & 8.3 & 29.1 & 14.3 & 20.2 \\ 60-65 & 4.8 & 12.5 & 12.9 & 4.8 & 7.9 \\ 65-75 & - & 4.2 & 9.7 & 14.3 & 5.0 \\ 75-85 & - & 4.2 & 3.2 & 4.8 & 2.2 \\ \text { TOTAL } & 100.0 & 100.0 & 100.0 & 100.0 & 100.0 \\ \text { AVERAGE } & \$ 51.31 & \$ 52.19 & \$ 56.69 & \$ 55.12 & \$ 53.24 \\ \text { MODE } & \$ 50-55 & \$ 45-50 & \$ 55-60 & \$ 45-50 & \$ 50-55\end{array}$

The average cost was $\$ 53.24$ in the sampled populations. Private referrals cost the most, with the average cost of $\$ 56.69$. Police referrals were the lowest, with the average cost of $\$ 51.31$. This is probably because of their closer proximity to the Multnomah County Hospital. The distribution is skewed toward higher costs and truncated at $\$ 45$.

\section{MEDICAL ASSESSMENT}

As explained in CHAPTER I, a medical assessment was obtained from the ambulance operators describing the condition of the Welfare recipient when picked up. These assessments were then given to Dr. James Landis, 
Medical Director for Public Welfare, who evaluated the assessments as to whether he felt an ambulance was needed or whether some other transportation modality could have been used, such as wheelchair or stretcher car services. He was uncertain of some of the sample assessments, so these were recorded in a separate column.

Medical Assessment Compared with Admissions and Transfers

TABLE XXIV shows the evaluation of medical assessments compared with whether the Welfare recipient was admitted to the hospital or not, or if he was a transfer, or if it was not known whether the Welfare recipient was admitted or a transfer, which is represented by the word "blank".

\section{TABLE XXIV}

MEDICAL ASSESSMENT COMPARED WITH ADMISSIONS AND TRANSFERS (PERCENTS WITH NUMBERS IN PARENTHESIS)

$\begin{array}{lcc}\text { AMBULANCE } & \text { AMBULANCE NOT } & \text { TOTAL } \\ \text { REQUTRED } & \text { REQUIRED } & \end{array}$

$\begin{array}{lrrrrrrrr}\text { ADMITTED } & 32.4 & (11) & 41.2 & (14) & 26.4 & (9) & 24.5 & (34) \\ \text { NOT } & & & & & & & & \\ \text { ADMITTED } & 37.5 & (24) & 45.3 & (29) & 17.2 & (11) & 46.0 & (64) \\ \text { TRANSFER } & 7.1 & (2) & 85.7 & (24) & 7.1 & (2) & 20.1 & (28) \\ \text { BLANK } & 23.1 & (3) & 30.8 & (4) & 46.1 & (6) & 9.4 & (13) \\ \text { TOTAL } & 28.8 & (40) & 51.1 & (71) & 20.1 & (28) & 100.00 & (139)\end{array}$

The data shows over half of the ambulance trips $(51.1 \%)$ did not require an ambulance. Only $28.8 \%$ required an ambulance, and it was uncertain whether $20.1 \%$ needed an ambulance or not. Admissions did not 
prove to be a good indicator of the need for ambulances. In fact, fewer Welfare recipients were admitted who required an ambulance than who did not, and there were more recipients requiring ambulances who were not being admitted than who were admitted.

The percentage of ambulances that were not required in relationship to transfers is quite significant (85.7\%). If the medical assessment is a valid independent variable, this would indicate that transfers should not in most cases use an ambulance. In numbers, only two welfare recipients in the sample required an ambulance when being transferred, and probably some of the six that Dr. Landis was uncertain about may have also required an ambulance. This may be an important area in which to establish some control through Welfare policy revision.

At one time Public Welfare wanted to pay for only those Welfare recipient ambulance trips that were admitted to a hospital. Our figures indicate that admissions would not be a valid indicator for the need for ambulance service. It appears that need for ambulance transportation may not necessarily mean hospitalization but implies a need for medical treatment on the basis of the medical assessments. It is interesting that the number of required ambulances ( 40 or $28.8 \%$ ) is close to the number of admissions ( 34 or $24.5 \%$ ), and that those not admitted (64 or $46 . \%$ ) corresponds closely to the number not requiring an ambulance ( 71 or $51.1 \%)$.

\section{Medical Assessment Compared with Lights and Sirens}

Ambulances are emergency vehicles equipped with lights and sirens and are authorized by the State Highway Commission to use their lights and sirens in emergency situations and to exceed the speed limit 10 miles 
per hour. A comparison is made in TABLE XXV between the medical assessment given by Dr. Landis as to whether an ambulance was required, was not required or was uncertain, and whether or not lights and sirens were used in the transporting process.

TABLE XXV

MEDICAL ASSESSMENT COMPARED WITH

USE OF LIGHTS AND SIRENS*

\begin{tabular}{|c|c|c|c|c|}
\hline $\begin{array}{l}\text { LIGHTS } \\
\text { SIRENS }\end{array}$ & $\begin{array}{l}\text { AMBULANCE } \\
\text { REQUTRED }\end{array}$ & $\begin{array}{l}\text { AMBULANCE NOT } \\
\text { REQUIRED }\end{array}$ & UNCERTAIN & $\begin{array}{c}\text { TOTAL } \\
\text { (WEIGHTED) }\end{array}$ \\
\hline No & $14.6 \quad(14)$ & $63.6 \quad(61)$ & 21.9 & 69.1 \\
\hline YES & $60.5 \quad(26)$ & $23.3 \quad(10)$ & 16.3 & 30.9 \\
\hline TOTAL & $28.8 \quad(40)$ & $51.1 \quad(71)$ & 20.1 & $100.0(139)$ \\
\hline
\end{tabular}

*Percents, numbers in parenthesis

The data above indicates $60.5 \%$ or 26 ambulance runs with lights and sirens required an ambulance and $63.6 \%$ or 61 cases without lights and sirens did not require an ambulance. This is highly critical and suggests that time is an element in defining the role of an ambulance. Where there is a need to transport a person immediately with all speed to a medical facility as indicated by use of lights and siren, an ambulance is required. Where time is not an important factor, alternative modalities of transportation could be used.

\section{Medical Assessment Compared with Programs}

The following table compares the medical assessment with programs, showing the number and their percentages: 
TABLE XXVI

\begin{tabular}{|c|c|c|c|}
\hline \multicolumn{3}{|c|}{$\begin{array}{c}\text { MEDICAL ASSESSMENT COMPARED } \\
\text { WITH PROGRAMS }\end{array}$} & \\
\hline PROGRAM & $\begin{array}{l}\text { AMBULANCE } \\
\text { REQUIRED }\end{array}$ & $\begin{array}{l}\text { AMBULANCE NOT } \\
\text { REQUIRED }\end{array}$ & UNCERTAIN \\
\hline OAA & $24.1 \quad$ (13) & $51.9 \quad(28)$ & $24.1 \quad(13)$ \\
\hline $\mathrm{ADC}$ & $50.0 \quad(3)$ & $33.3 \quad(2)$ & 16.1 \\
\hline $\mathrm{AB}$ & - & $100.0 \quad(2)$ & - \\
\hline $\mathrm{AD}$ & 29.0 & $48.4 \quad(30)$ & 22.6 \\
\hline GA & 40.0 & $60.0 \quad$ (9) & - \\
\hline
\end{tabular}

The percentages show that GA recipients have the highest percentage of ambulances that were not required $(60.0 \%)$, OAA recipients are second $(51.9 \%)$, and $\mathrm{AD}$ recipients are third $(48.4 \%)$.

Medical Assessment Compared with Referrals

TABLE XXVII shows the number and percentage of referrals that required ambulances, did not require ambulances, or where the appropriateness of ambulance transportation was uncertain. 
TABLE XXVII

MEDICAL ASSESSMENT COMPARED

WITH REFERRAL

(PERCENTS WITH NUMBERS IN PARENTHESIS)

\begin{tabular}{|c|c|c|c|}
\hline REFERRAL & $\begin{array}{l}\text { AMBULANCE } \\
\text { REQUTRED }\end{array}$ & $\begin{array}{l}\text { AMBULANCE NOT } \\
\text { REQUIRED }\end{array}$ & UNCERTAIN \\
\hline POLICE & $42.8 \quad(27)$ & $39.7 \quad(25)$ & $17 \cdot 5$ \\
\hline WELFARE & 8.3 & $62.5 \quad(15)$ & 29.2 \\
\hline PRIVATE & 25.8 & $45.2 \quad(14)$ & 29.0 \\
\hline COUNTY & 14.3 & $81.0 \quad(17)$ & 4.7 \\
\hline
\end{tabular}

This data is revealing. It indicates, providing that the assessment criteria was valid, that police are making the most appropriate ambulance referrals or requests. It shows that Welfare is making the most inappropriate referrals with County following closely. County is making the most referrals in percentage where ambulances are not required and Welfare follows County. What this implies is uncertain. Professional people are charged with the responsibility of using resources appropriately in their best judgement. These figures indicate the professionals are the ones who are making the most inappropriate referrals. This might possibly lie within their perceptions of what is appropriate. Lack of definition or the lack of criteria from which to make judgements could be the key in resolving this dilemma. It is apparent that some definition and criteria are needed to make appropriate referrals in requesting ambulances.

\section{ADMISSIONS AND TRANSFERS}

$\underline{\text { Admissions and Transfers Compared with Lights and Sirens }}$

Using admissions as the independent variable, the following summary was compiled. Admissions were thought to be a good indicator of medical 
need in the past by Welfare Staff. As indicated before, when comparing admissions with medical assessments, admissions were not a good indicator of the need for ambulances.

TABLE XXVIII compares hospital admissions, transfers, and blanks (unknown whether admitted or transferred) with lights and sirens.

\section{TABLE XXVIII}

ADMISSIONS AND TRANSFERS COMPARED

WITH LIGHTS AND SIRENS

(PERCENTS WITH NUMBERS IN PARENTHESIS)

\begin{tabular}{lcccccccccc} 
LIGHTS & \multicolumn{9}{c}{ NIRENS } & \multicolumn{2}{c}{ ADMITTED } & \multicolumn{2}{c}{ ADMITTED } & TRANSFER & \multicolumn{2}{c}{ BLANK } & \multicolumn{2}{c}{ TOTAL } \\
N0 & 18.8 & $(18)$ & 42.7 & $(41)$ & 28.1 & $(27)$ & 10.4 & $(10)$ & 69.1 & $(96)$ \\
YES & 37.2 & $(16)$ & 53.5 & $(23)$ & 2.3 & $(1)$ & 7.0 & $(3)$ & 30.9 & $(43)$ \\
TOTAL & 24.5 & $(34)$ & 46.0 & $(64)$ & 20.1 & $(28)$ & 9.4 & $(13)$ & 100.0 & $(139)$
\end{tabular}

More were not admitted than admitted when lights and sirens were used. Most transfers did not require lights. This indicates that admissions are not a good indicator of ambulance need.

Admissions and Transfers Compared wi th Programs

TABLE XXIX shows the programs the Welfare recipients are in and compares this to whether they were admitted or transferred. 
TABLE XXIX

$$
\begin{aligned}
& \text { ADMISSIONS AND TRANSFERS COMPARED } \\
& \text { WITH PROGRAM } \\
& \text { (PERCENTS WITH NUMBERS IN PARENTHESIS) }
\end{aligned}
$$

\begin{tabular}{lccccccccc} 
PROGRAM & \multicolumn{1}{c}{ ADMITTED } & \multicolumn{3}{c}{ NOT } \\
ADMITTED & \multicolumn{2}{c}{ TRANSFER } & \multicolumn{2}{c}{ BLANK } \\
OAA & 33.3 & $(18)$ & & 20.4 & $(11)$ & 31.5 & $(17)$ & 14.8 & $(8)$ \\
$\mathrm{ADC}$ & - & & 83.3 & $(5)$ & - & & 16.7 & $(1)$ \\
$\mathrm{AB}$ & - & & 50.0 & $(1)$ & 50.0 & $(1)$ & - & \\
$\mathrm{AD}$ & 19.3 & $(12)$ & 61.3 & $(38)$ & 14.5 & $(9)$ & 4.8 & $(3)$ \\
$\mathrm{GA}$ & 26.7 & $(4)$ & 60.0 & $(9)$ & 6.7 & $(1)$ & 6.7 & $(1)$
\end{tabular}

The data indicates more OAA recipients are admitted to the hospital than any other group. Outside of the percentage for AB program recipients $(50 \%)$, there are more OAA transfers than in any other program. This also seems to correlate well with age. It seems that the older the age representation is, the more admissions there are proportionately. Admissions and Transfers Compared With Referrals

The last table shows admissions, transfers, and blanks and compares them with referral source. 
TABLE XXX

ADMISSIONS AND TRANSFERS
COMPARED WITH REFERRAL
(PERCENTS IITH NUMBERS IN PARENTHESIS)

\begin{tabular}{|c|c|c|c|c|}
\hline \multicolumn{5}{|c|}{ NOT } \\
\hline REFERRAL & ADMITTED & ADMITTED & TRANSFER & BLANK \\
\hline POLICE & (13) & 68.3 & $1.6 \quad(1)$ & 9.5 \\
\hline WELFARE & 25.0 & 37.5 & 29.2 & 8.3 \\
\hline PRIVATE & $35.5 \quad(11)$ & $38.8 \quad(12)$ & $9.7 \quad(3)$ & 16.1 \\
\hline COUNTY & $19.1 \quad(4)$ & - & $81.0(17)$ & - \\
\hline
\end{tabular}

This data suggests that private referrals have the most admissions and police make the most referrals where the Welfare recipient is not admitted. This is almost opposite from the breakdown by medical assessment.

\section{SUMMARY}

In summary, the average patient was an $0 \mathrm{AA}$ or $\mathrm{AD}$ recipient, transported from home or other unsymbolized place or a congregate care facility to the Multnomah County Hospital, having been referred by the police during the 9 a.m. to $1 \mathrm{p} . \mathrm{m}$. period, during summer or fall, with an average cost of $\$ 53.24$ per trip, for almost four trips during the year and a half period. About $83 \%$ of the Welfare recipients were transported for medical reasons, $27 \%$ of whom were admitted to the hospitals, with $29 \%$ of the patients judged as having required an ambulance. 
CHAPTER V

\section{ANALYYSIS AND RECOMMENDATIONS}

\section{WELFARE'S PRESENT PROGRAM}

This researcher feels that many of the perceived probIems of Welfare staff are engrained within the present program structure. The vagueness of the program as discussed in Chapter II comes from a lack in program definition, guidelines and policy. Public Welfare has traditionally had limited funds to work with in all areas of delivering services and in income maintenance grants. It only seems logical that if there are limited funds for Medical Transportation, some decision has to be made about the limitations of the Medical Transportation program. This chapter focuses on this issue and suggests possible ways of redefining and setting program boundaries in administering this social service. The first task here will be to critique these rules and regulations that appear problematic. (See Appendix)

\section{$\underline{\text { Rule Two - Authorization (1) }}$}

During Public Welfare Branch Office hours, non-emergent transportation must be prior authorized by the Public Welfare Branch Office on PWD-501B, Medical Transportation and Authorization Invoice, indicating the specific transportation which can be provided at Public Welfare expense. Non-emergent transportation provided during hours when the Public Welfare Branch Office is closed or emergent transportation must be reported to the Public Welfare Branch as soon as feasible but not later than the next work day. Authorization of the specific service and specific charge for that service is given by the Public Welfare Branch Office on PWD-501B. This form is prepared by the Public Welfare Branch office only if funds are available to cover the charge for that service. 
This rule regarding non-emergent transportation is defective. The rule states that during working hours non-emergent transportation must be prior authorized; however, when the Welfare office is closed the situation has to be reported the following day. The rule does not hold up because people who do not want to go through the hassle of prior authorization can avoid this by waiting until after office hours. Therefore, it is recomended that:

1. All non-emergent transportation be scheduled at least 24 hours in advance.

As documented elsewhere in this report, non-emergent situations are those situations in which the medical need does not require immediate treatment. Most medical non-emergent situations can be planned if planning is a requirement. It is human nature to put things off that do not require planning until the last minute. Most doctor's appointments, medical exams and physical therapy sessions are scheduled. It seems reasonable that the transportation of the individual to and from that source could also be scheduled as the rule. It is therefore recommended that:

2. A district transportation coordinator position be established.

This coordinator would be responsible for establishing a liaison betweem transportation companies (i.e. taxis, servi-car, wheelchair and stretcher car companies), and those authorizing the transportation (i.e. Welfare case workers). It still may seem appropriate for Welfare recipients to go through their caseworkers for authorization. However, with the County Physician's office and congregate care staff, transportation would have already been scheduled, thereby reducing significantly their role as a referral soürce. 
Also, there are economical advantages to this. First, of course, would be a "pooling" process. Taxi companies have offered reduced rates for scheduled trips for more than one individual. Stretcher and wheelchair cars can be obtained for less than half the cost of ambulances. Many Welfare recipients go to the Multnomah County Hospital or the University Hospital for appointments during the same time period. These could be "pooled". It seems possible that patients being transferred from a hospital to a nursing home could also be "pooled". The possibilities for this are manifest and will only take some imagination and experience to find ways of working with economies of scale.

The modality of transportation should also be carefully considered. The rule should be to match the medical need with the resources of a carrier. It is doubtful whether ambulances should be used for nonemergent situations. Stretcher and wheelchair cars are equipped almost the same as ambulances. In fact, A.A. Ambulance uses an ambulance for their stretcher car services. However, stretcher cars and wheelchair cars don't generally have the emergency lights and sirens and they are staffed by one man instead of two. In most cases, if a person is in a critical condition that would require an attendant, the person shouldn't be transported from a hospital, but if it is to a hospital, some latitude should be given. Therefore it is recommended that:

3. Use of ambulances for non-emergent Medical Transportation should be prohibited unless a physician's statement is issued giving the medical need.

The medical consultant could be used to audit these need statements which would be helpful in coming up with some criteria that would clearly 
differentiate between non-emergent and emergent.conditions so controversial over the past few years among physicians.

It is through the process of establishing priorities within nonemergent transportation that the boundaries of the program service area can be defined. It is clear that transportation for routine medical checkups should be lower in priority than transportation for a major operation. This can be differentiated by criteria of primary and preventive health needs. It is true that we all want to be generously benevolent to our fellow men, but when limited resources are available there is a reality that must be faced.

Rule Three - Emergent Transportation

Emergent transportation is generally provided by ambulance. A sudden unexpected occurrence generally creates an emergency. A physician's statement will best define the medical need and thereby identify an emergency. Other guidelines to identify an emergent situation requiring transportation by ambulance are a call for an ambulance following a traffic accident, a call to which the carrier has no reasonable alternative but to immediately dispatch an ambulance, and similar situations which create an identifiable emergency.

It is true, at least in Portland, that emergent transportation is generally provided by ambulances. However, a sudden, unexpected occurrence is only part of what creates an emergency. Funk and Wagnalls Standard College Dictionary defines emergency as, "A sudden and unexpected turn of events calling for immediate action". This is critical in understanding the nature of an emergency. Time is of the essence in emergency transportation. An ambulance has the proper equipment and staff to give initial treatment and to deliver the patient to a hospital with speed. Immediate treatment to save life or limb is the primary objective. This transcends all systems of the delivery of health care without respect to 
financial coverage, family physicians, Welfare policy or choice of alternatives.

Since a physician is generally not at the scene to identify an emergency, his statement does not define the emergency, it only validates the need for medical treatment when the patient was treated by him. The emergency is defined by the person or people there and their perceptions of the medical need. Also, a traffic accident does not define a medical emergency. More people walk away from traffic accidents slightly or uninjured than injured. This is an area in which there can be little control. Only through education in identifying medical needs can any control be established. It is therefore recommended that:

4. Emergencies be redefined emphasizing time

and

5. Collaboration and support be given by Public Welfare to those entities presently engaged in the educational effort to make the public more self-reliant or knowledgeable of intermediate health measures.

Rule Three goes on to state:

In emergent situations, the Public Welfare Division will assume only the expense of transporting the patient to the nearest facility where the emergent medical need can be met. Unless authorized by the Public Welfare Branch Office transportation from one community to another community. will not be paid by the Public Welfare Division.

Even though the above is policy, what is actually happening is that people are being transported to where they want to go. As stated by one ambulance operator, an injured person is in his most disoriented state and cannot always be the best judge of where he wants to go. The problem here lies in existing statutes of the State of Oregon. The Good Samaritan 
Law hinders medical technicians fxom making judgments which seem more reliable than the injured or sick person. It is therefore recommended that Public Welfare:

6. Support the Good Samaritan Law Amendment.

There might also be a problem of identifying Welfare recipients. This is a difficult problem. Welfare provides identification cards to Welfare recipients; however, unless the person is known by the ambulance drivers or unless the question is asked if they are under any insurance program or Welfare program, there is no way of knowing.

It is not recommended that emergent transportation be prior authorized because this would take up unnecessary time, and telephone interviews would not remedy any problem. It has been stated by police dispatchers that it is almost impossible to extract enough information over the telephone to identify the need for ambulance transportation. Thus, by establishing a 24 hour switchboard for authorization, medical needs could not be identified any more than under the present system.

\section{Rule Four - Type of Transportation}

The choice of carrier will be determined by the patient's medical condition, distance to the place of treatment, and availability of suitable carrier, utilizing the least expensive conveyance consistent with these conditions.......

The patient's medical condition is the key. It appears necessary that some criteria be established that links medical need with transportation modality. It is recommended that:

7. Criteria be established that links medical need with transportation modality. 
In order to accomplish this task it would be helpful to collaborate with the medical community as it is they who will be the most resistant to this policy change.

\section{$\underline{\text { Rule Five - Public Rates }}$}

......The charges to the Public Welfare Division by any type of carrier will in no event exceed the charges to the general public for like services. Any carrier can by agreement with the Public Welfare Division or local Public Welfare Branch office charge the Public Welfare Division at rates less than those charged the general public for like services.

Many medical services have been audited, and charges which are fair have been established. All major medical insurance companies have maximums established for different medical treatments. It seems only logical that Public Welfare audit ambulance companies and come up with a fair fee. As stated before, up to last year Multnomah County was paying $\$ 37$ per trip to ambulance companies for indigents. How this price was derived is not known. However, when Public Welfare in 1970 tried to reduce the rates to this amount there was much resistance and it was stated that Welfare could not arbitrarily establish and impose rates. It is realized that politics play an important role in this process. Federal matching of funds (50\%) for this service bring additional dollars into the state. However, because of rising costs and fewer dollars in proportion for provision of funds for this service, it seems necessary that some control be established over the service charges. It is therefore recommended that:

8. Public Welfare or some other source audit ambulance companies and establish a flat fee charge. 
The reason for a flat fee is that it reduces accounting expenses. Some ambulancee companies have very complicated additional charges which make it difficult to audit and verify. An alternative to this would be to have the city or some other government agency regulate charges by ordinance in the same way garbage rates are established or utility company rates are established under public supervision.

\section{EMERGENCY HEALTH SERVICES}

\section{Ambulances}

As stated, it is recommended that an audit should be done to make a determination of a fair fee. In most cases, except when the patient is unconscious, there is an attempt to identify the patient. If a patient can be identified as a Public Welfare recipient, it might be possible to establish a standard procedure for ambulance operators to follow, such as taking the patient to certain hospitals.

With ambulance technicians increasing their knowledge and skills it seems reasonable that at times the technician may not feel the need to transport a person by ambulance. Some arrangement could be made in paying the ambulances a response fee in this situation. However, before this can take place the problem of ambulance operator liability still remains. Without the amendment to the Good Samaritan Law, ambulance operators are stili liable and they probably would not endorse such a procedure. Hospital Emergency Treatment Units

Hospital emergency treatment units have problems similar to ambulances, mainly over-utilization. Their solution was to provide easy access to alternative out-patient medical facilities located either at the 
hospital or in the community. It seems logical that the same solution can be applied to the ambulance over-utilization problem; that is, by providing easy access to cheaper alternative methods of transportation. For example, do taxi companies take medical identification cards for transportation of Welfare recipients for medical reasons? It was suggested by an ambulance operator that Welfare recipients request ambulances because they don't have cab fare. It seems that a certain amount of judgment and latitude on the recipients' behalf would be in order if this were the case. This contradicts the prior scheduling recommendation suggested earlier but is suggested for the exceptional case. This is the situation where the medical need does not require an ambulance but the situation requires medical treatment before the person can be scheduled for transportation. This could happen on a weekend, holiday, or evening when a Welfare recipient cannot get in touch with Public Welfare or staff. $\underline{\text { Police }}$

This researcher feels that the police dispatch system is inferior to other emergency communication systems. It is based on political and economic purposes which are not advantageous to the welfare of the community. Even though they are doing the best job in screening ambulance referrals, this is not their function or role. It is recommended that:

9. Public Welfare recommend and support the "911" system Pacific Northwest Bell has been proposing.

The Medical Profession

As discussed in Chapter III, the Multnomah County Medical Society is against categorizing types of medical transportation. Their argument was for stricter regulations and the chance of a secondary medical problem 
becoming a primary emergency medical problem. The Multnomah County Health Officer also took a position on this. It seems necessary to attempt a compromise within these groups. Without the medical profession's support any proposed changes will fail.

\section{The Public}

As stated earlier, the primary focus should be in education on emergency health measures and resources. Public Welfare could do this in the casework process or by distributing literature to recipients. However, the main emphasis should be in collaborating with other institutions for an over all education effort. The person making the ambulance referral is not always the Welfare recipient. Therefore it is recommended that: 10. Public Welfare support the Comprehensive Health Planning Association recommendation for a 24 hour central referral and informational number to which the public can turn for assistance.

This proposal of the Comprehensive Health Planning Association would enhance public information output resources and serve as an aid to Welfare recipients in handling problems that are normally handled by Welfare Staff. David P. Hooper Alcoholic Recovery Center

The present site for this resource has been condemned by the city because of fire and construction hazards. There have been problems in relocating. One point of reference is that they will undoubtedly move out of the skid row area. Since the Rapid Outreach Police Intake System (ROPIS) was started, the Detoxification Center staff does not feel that relocating will be dysfunctional to access. They still plan to operate a storefront station in the area and the cruiser will continue to pick up alcoholics. This is a program that should be watched carefully. Since 
there are between four and five hundred Welfare alcoholics in the skid row area, the support of Public Welfare is critically needed.

\section{WEST BRANCH STUDY}

The West Branch Study provided a lot of data which indicates the vagueness and complexity of ambulance transportation. The recommendations that are stated come from an analysis of Public Welfare policy and the West Branch study in relationship to other components within the emergency medical care system. It is felt by this researcher that the problems are manifest in the total Medical Transportation Program and not in any specific area or branch.

One thing not mentioned before emerging from this study is that in one out of every ten ambulance trips, the patient was intoxicated. Because of the population, this Branch has unique characteristics that must be noted. They are serving a large number of alcoholics and the solution to part of their problem lies in giving support to alcoholic programs. One person in the sampled population has had 38 ambulance trips in the year and a half covered. Each time this person was transported by ambulance he was picked up off the street, referred by a police officer, drunk, and in a seizure. This example indicates a need for closer contact with Welfare recipients and having information about medical problems. If the caseworker had known about this, there may have been some alternative arranged for this Welfare recipient that would have reduced the cost to Welfare and the suffering this person must have experienced. It is therefore recommended that: 
11. Caseworkers be provided with a summary report at least once every three months on their assigned caseload medical expenses.

It is clear from this study that Welfare staff is not a good referral source. The information they obtain is too vague in order to make appropriate judgments. It appears that decision should be made by the person at the scene, especially in emergent situations. In non-emergent situations some investigation could be done before scheduling to obtain the necessary information in order to make judgments.

Since $83.5 \%$ of the users of ambulances in West Branch were from $\mathrm{OAA}$ and $\mathrm{AD}$ programs, the emphasis in medical investigations should be placed primarily in these two areas. The OAA usage is understandable, but the $A D$ usage seems to be out of control. This could indicate a need for lower caseloads in the $A D$ program.

As far as key indicators to determine the need for ambulance transportation, lights and sirens and transfers based upon Dr. Landis's evaluation of assessments were the best. It is ironic in a way that lights and sirens would prove valid, but it was the key to defining an emergent situation. It would not be recommended to use this as an indicator in the future for certainly as soon as cextain ambulance operators find this out, the light will go on. Transfers should be controlled and will be if prior scheduling is required. 


\section{CONCLUSION}

This researcher feels that the readers of this study may come up with different conclusions from the ones he feels are relevant. Because of the complexity of the issues described within this study, other conclusions will be omitted and left for the reader to interpret on his own. However, the recommendations will be reiterated here for reference.

1. All non-emergent transportation be scheduled at least 24 hours in advance.

2. Establishment of a District Transportation Coordinator position.

3. Use of ambulances for non-emergent medical transportation be prohibited unless a physician's statement is issued stating the medical need.

4. Emergencies be redefined to emphasize time.

5. Collaboration and support be given by Public Welfare to those entities presently engaged in the educational effort to make the public more self-reliant or knowledgeable of intermediate health measures.

6. Support the Good Samaritan Law amendment.

7. Criteria be established that links medical need with transportation modality.

8. Audit ambulance companies and establish a flat fee charge.

9. Public Welfare recommend and support the "911" system that Pacific Northwest Bell has been proposing.

10. Public Welfare support the Comprehensive Health Planning Association's recommendation for a 24 hour central referral and informational number to which the public can turn for assistance.

11. Caseworkers be provided with a summary report at least once every three months on their assigned caseload medical expenses. 


\section{REFERENCES}

1. State of Oregon Department of Human Resources, Public Welfare Division, Guide for Medical Transportation Services, Book B, Section VI, Part II, Reissued/Revised on March 1, 1973, (Salem, Oregon), p. 5 .

2. Ibid., p. 5 .

3. Ibid., p. 6 .

4. Ibid., p. 6 .

5. Ibid., p. 7 . 


\section{BIBLOGRAPHY}

Burch, John. Ambulance Transportation. Mimeographed. Multnomah County Public Welfare. Portland, Oregon. August 24, 1970.

Capps, Douglas. Mayors Policy Statement on Emergency Ambulance Care. Mimeographed. City of Portland. September 29, 1973. Portland, Oregon.

Comprehensive Health Planning Association for the Metropolitan Portland Area. Report of the Committee on Fmergency Medical Care Systems in Clackamas, Columbia, Multnomah and Washington Counties. Mimeographed. Comprehensive Health Planning Association. 1971. Portland, Oregon.

Cunneen, James; Assistant Administrator for Business Services, Multnomah County Public Welfare. Budget and Expenditure Data. Unpublished monthly report. August, 1970. In possession of Multnomah County Public Welfare. Portland, Oregon.

Domke, D. E., M.D.; Medical Director, Public Welfare Division. Letter to Gordon Gilbertson, District, Manager, Multnomah County Public Welfare. September 30, 1970. Unpublished. In possession of Multnomah County Public Welfare, Portland, Oregon.

Donnelly, John H., M.D., M.P.H.; Multnomah County Health Officer. Letter to Gordon Gilbertson, District Manager, Multnomah County Public Welfare. August 18, 1970. Unpublished. In possession of Multnomah County Public Welfare. Portland, Oregon.

"Family Blames Ambulance System for Lost Life". Oregon Journal. 17 March 1973.

Goss, Walter A., M.D.; Multnomah County Health Officer. Letter to City of Portland. Unpublished. In possession of Portland Mayor's Office, City of Portland, Portland, Oregon.

Logan, Norman, M.D.; Multnomah County Medical Society. Letter to City of Portland. Unpublished. In possession of Portland Mayor's Office, City of Portland, Portland, Oregon.

Multnomah County Government Accounting Office. Report on Police Dispatched Ambulances. April 26, 1972. Unpublished. In possession of Portland Mayor's Office, City of Portland, Portland, Oregon. 
Office of PEPD. The First Step; David P. Hooper Alcoholic Recovery Center Follow-up Evaluation. Portland, Oregon. June 25, 1973.

Oregon Public Welfare Division. Medical Assistance in Oregon. PAM 9006. Revised $1 / 73$. State of Oregon Department of Human Resources. Salem, Oregon.

Oregon Public Welfare Division. Oregon's Public Welfare Programs and Services. PAM 9007A. Revised 1970. State of Oregon Department of Human Resources. Salem, Oregon.

Portland City Club. Report on Emergency Care to the Injured and Stricken in The Portland Area. September 9, 1966. Vo1. 47, No. 15. City Club of Portland. Portland, Oregon.

Portland City Club. Supplemental Report on Emergency Care to the Injured and Stricken in The Portland Area. July 31, 1970. City Club of Portland, Vol. 51, No. 9, Portland, Oregon

State of Oregon. Legislation Relating to Public Welfare Division of the Department of Human Resources. State of Oregon. 1971-1973. 
SHOI

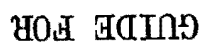

XIaNiddd 
T A B L E OF C O N TEN T S

$\underline{\text { SUBJECT }}$

$\underline{\text { PAGE }}$

Foreword ................... 3

Rules and Regulations............ 6

Eligibility, Billing Forms, and

Billing Procedures . . . . . . . . . . 9 


\title{
To Medical Transportation Services
}

\begin{abstract}
Transportation to and from a source of medical care or between medical facilities is recognized by the Public Welfare Division as a necessary part of medical care. The amount of funds available within the welfare budget of a particular branch for medical transportation services establishes the limitations of payment by the Public Welfare Division regardless of type of transportation utilized or the situation which required transportation services.
\end{abstract}

The Public Welfare Branch Office will make full use of the resources available from all sources and other agencies for providing funds for or medical transportation service and thus conserve public welfare medical monies; i.e., insurance; Crippled Children's Division; State Accident Insurance Fund; Motor Vehicle Accident Fund; Veterans' Administration; Blind Commission; volunteer groups; Title XVIII (Medicare); personal auto of relatives, friends or volunteer associations; etc.

The Oregon Public Welfare Division

Public Service Building

Salem, Oregon 97310 
Governing Medical Transportation Services

The following rules are hereby established by the Public Welfare Division by authority vested in said Division by ORS $411.060 ; 411.070$ and 414.065 for the purpose of supervision and control of medical services rendered to those clients eligible to receive such services under the provisions of Oregon State Statutes. These rules and regulations are subject to change at the discretion of the Division.

\section{Rule One \\ Relationships}

These rules and regulations shall govern the relationships between the Division and those providing medical transportation to welfare clients. Authorization for payment of and the rates payable for medical transportation are prescribed by the rules and regulations in this guide.

\section{Rule Two}

Authorization

During Public Welfare Branch Office hours, non-emergent transportation must be prior authorized by the Public Welfare Branch Office on PWD-501B, Medical Transportation and Authorization Invoice, indicating the specific transportation which can be provided at Public Welfare Division expense. Non-emergent transportation provided during hours when the Public Welfare Branch Office is closed or emergent transportation must be reported to the Public Welfare Branch Office as soon as feasible but not later than the next work day. Authorization of the specific service and specific charge for that service is given by the Public Welfare Branch Office on PWD-501B. This form is prepared by the Public Welfare Branch Office only if funds are available to cover the charge for that service.

Rule Three

Emergent Transportation

Emergent transportation is generally provided by ambulance. A sudden unexpected occurrence generally creates an emergency. A physician's statement will best define the medical need and thereby identify an emergency. Other guidelines to identify an emergent situation requiring transportation by ambulance are a call for an ambulance following a traffic accident, a call to which the carrier has no reasonable alternative but to immediately dispatch an ambulance, and similar situations which create an identifiable emergency. 
In emergent situations, the Public Welfare Division will assume only the expense of transporting the patient to the nearest facility where the emergent medical need can be met. Unless authorized by the Public Welfare Branch office transportation from one community to another community will not be paid by the Public Welfare Division.

\author{
Rule Four \\ Type of Transportation
}

The choice of carrier will be determined by the patient's medical condition, distance to the place of treatment, and availability of a suitable carrier, utilizing the least expensive conveyance consistent with these conditions. If friends or relatives can provide the required transportation, the cost will not be paid by the Public Welfare Division as a medical expense.

The term "carrier" is wide in scope; i.e., private car, city bus, intercommunity bus, taxi, ambulance, chair car, wheelchair coach, servi-car, train, chartered plane, etc.

Payment will be authorized by the Public Welfare Branch Office for the type of medical transportation adequate for the patient's condition, with consideration given to the least expensive mode of transportation. Ambulances should not be required to wait, as such time is billed; also, while ambulance or taxi transportation may be required to a medical facility, a less expensive mode may be adequate for the return of the patient.

Public Welfare Branch Offices and carriers will work cooperatively toward scheduling trips on the least busy days, and most convenient hours during those days, for the carriers, and will also make every effort to transport more than one patient on a single trip when appropriate. Such arrangements will reduce charges as may be agreed to between the carrier and Public Welfare Branch Office.

Transportation of deceased clients is a mortuary expenditure to be paid from public assistance maintenance funds.

Rule Five

Public Rates

In order to qualify for payment by the Public Welfare Division, a carrier doing business as a provider of ambulance, chair car, wheelchair coach or servi-car services shall:

1. File with the Public Welfare Division a current public rate schedule of charges accompanied by Form PWD-504, Certification for Payment of Medical Transportation Services by Oregon Public Welfare Division at Public Rates, Exhibit No. 3, page 21 of this guide. Rates can be changed only by filing an amended public rate schedule, accompanied by a Form PWD-504; rate changes wili be effective on the first day of a month but not less than 30 days following the date of filing. In no event will the effective date of the change in rates precede the date such rates are effective for the general public. 
2. Customarily charge the general public at those rates specified above and routinely pursue unpaid charges in anticipation of collection.

3. Permit the Division the privilege of auditing the carrier's financial records at any time following notification to the carrier of its plans to so audit. Such an audit would be done to assure the Public Welfare Division that this Rule Five is in full force and effect; that the charges to the Public Welfare Division do not exceed reasonable charges for transporting welfare clients; and that the charges do not exceed those rates filed by the carrier with and approved by the governmental body, if any, supervising and approving such rates.

The charges to the Public Welfare Division by any type of carrier will in no event exceed the charges to the general public for like services. Any carrier can by agreement with the Public Welfare Division or local Public Welfare Branch Office charge the Public Welfare Division at rates less than those charged the general public for like services.

Rule Six

Forms and Billing Procedure

The forms and billing procedure set forth in this guide will be followed in billing the Public Welfare Division for all transportation rendered and authorized by the Public Welfare Branch Office.

$\underline{\text { Rule Seven }}$

Billing Date

Bills for authorized transportation are to be filed with the Division prompty following service but in any event not later than the month following the month of service.

Rule Eight

Ful1 Payment Schedule

Payments provided by the Division for specific authorized services represent full and total payment for those services under the Division's medical services program.

Under no circumstances shall patients, relatives or friends be charged any amount to supplement fees paid by the Division for services to which they are entitled by 1 aw and rules and regulations established by the Division, and the carrier has no claim against the patient's estate for any charges for such services. 
Rule Nine

Use of Alternative Resources

As stated in the Foreword to this guide, the Public Welfare Branch Office will make full use of the resources available from all sources and other agencies providing funds for medical transportation or medical transportation service and thus conserve public welfare medical monies.

For those clients 65 years of age and older, every effort must be made by the ambulance company to use fully the ambulance benefit of Part " $B$ " of Public Law 89-97, Medicare, prior to billing the Public Welfare Division. Billing instructions are set forth elsewhere in this guide. 
ELIGIBILITY, BILLING FORMS,

AND

BILLING PROCEDURES 


\section{Medical Care Identification Card,}

Medical Transportation and Authorization and Invoice, PWD-501B, and

Request for Medicare Payment, Social Security Administration, Form SSA-1490W(OR)

I. WELFARE ELIGIBILITY--Eligibility status of the patient will be of critical importance to the provider of medical transportation, herinafter referred to as the "carrier"。 Eligibility may be determined as follows:

A. Medical Care Identification Card, PWD-1407--Issued by the Public Welfare Division to most welfare recipients. Recipients under some programs will not be provided with the cards, however. This card will certify to the eligibility of all members of the grant for the period of time specified, indicating the names and person letters of all recipients. This card is not to be construed as authorization for services since all medical transportation services must be authorized by the Public Welfare Branch Office within the limitations set forth in Rule Two of this guide.

B. Foster Child Medical Care Identification Card, PWD-1407A--Issued by the Public Welfare Division to eligible children in Foster Care. The name and person letter of the eligible child are shown on the card. See statement in paragraph "A" regarding authorization of medical transportation services.

C. Medical Transportation and Authorization and Invoice, PWD-501B (Exhibit 非)-In addition to certifying eligibility, this form will serve as authorization by the Public Welfare Branch office for medical transportation. Blank PWD-501B's will be issued, preheaded and partially completed, by the Public Welfare Branch Office and will indicate the specific services and amounts that are authorized.

The date when the Public Welfare Branch Office is contacted concerning a person not established as eligible under the Public Welfare Division Medical Assistance Programs is critical in establishing eligibility。 Ordinarily eligibility for medical assistance begins with the date of application. However, a decision to request medical assistance may be made during a period when Public Welfare Branch Office staff is unavailable; $i_{\circ} e_{\circ}$, during hours when the Public Welfare Branch Office is closed, Saturdays, Sundays and legal holidays. When this occurs the individual, or someone acting in his behalf, must apply to the Public Welfare Branch Office during the next working day. Eligibility then begins on the day the decision was made to apply for medical assistance. The promptness with which the carrier notifies the Public Welfare Branch Office on behalf of the individual of his name, other identifying information, and his intent to apply is important and may become a part of the application process。

II. PROCEDURE--Medical Transportation and Authorization and Invoice, PWD-501B

A. A recipient requiring medical transportation services will be more easily identified by the carrier when he contact the Public Welfare Branch Office 
for authorization of required service if the recipient presents an Identification Card. However, presentation of such a card is not a prerequisite to receiving medical transportation services.

B. The Public Welfare Branch Office will furnish a preheaded and partially completed PWD-501B, assuming the person is eligible and the service and expense are authorized by the Public Welfare Branch Office. PWD$501 \mathrm{~B}$ is the authorization form. The branch forwards the original and two copies to the carrier.

C. The carrier should make every effort to determine whether other funds are available to meet the costs of the service. Those funds are to be utilized before billing Welfare. However, if recovery from any of these sources is made by the carrier after payment by the Public Welfare Division, the carrier shall credit the Welfare Division accordingly--see the Foreword to all Vendors' Guides, Medical Assistance Programs, Public Welfare Division。

D. After services as authorized have been furnished, the carrier shall prepare his billing on the 501B. The carrier will retain the last copy and forward the original and one copy to:

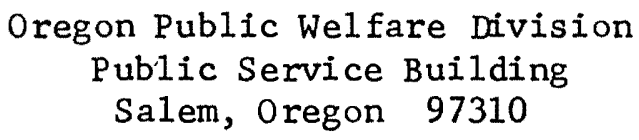

E. Care shall be exercised to insure that the billing includes the authorized service for only that recipient named by the branch office in the preheaded PWD-501B.

F. Payments will be made to the carrier on a collective basis; $i_{\circ} e_{0}$, a single check may be issued covering a number of invoices. A voucher will be furnished which will indicate by serial numbers the payments made for each invoice. Copies of invoices, form PWD-501B, will be returned to the vendor only in those instances where payment is not made as billed.

G. In general, the accounting and payment procedures of the Welfare Division function best when bills are mailed as soon as possible after the end of the month in which service was rendered, but not later than the end of the following month.

III。 COMPLETING THE INVOICE FORM PWD-501B

A. "Program/County/Case Number/Case Name" -- The branch office will complete.

B. "Name and Address of Vendor" -- The branch office will complete.

C. "Eligible Person for Whom Service Authorized" -- The branch office will enter the name of the peroon and person letter for whom the services are authorized. The carrier may bill only services that have been authorized for the person listed here. 
D. "Date of Service - Month/Day/Year" -- The branch office will complete.

E. "Authorizing Signature" and "Date" - The branch office will complete.

F. "Description of Services/Remarks" -- The branch office will clearly indicate the specific services authorized and maximum amount authorized for payment of those services. The purpose of the services, when significant, will also be indicated.

G. Column headed "Wel fare Complete" -- The branch office will complete.

\section{THE BILLING AREA}

H. "Vendor Complete in Detail or Attach Copy of Itemized Public Billing" -The carrier will complete carefully, entering all detail as appropriate. Attaching a copy of the itemized public billing relieves the carrier only of the responsibility of itemizing the services on the PWD-501B. The appropriate box, "A" through "H" must be checked, the amount billed must be noted, and the date of service must be stated.

The "Total" charge, "Insurance or Other Credits," and "Net Amount" must be indicated.

NOTE: The procedure for handling credits for payments received from other resources prior or subsequent to billing is set forth in the Foreword to all Vendors' Guides, Medical Assistance Programs, Public Welfare Division.

The branch office or ambulance company will indicate if the services were required as the result of an accident or injury.

The carrier must enter the appropriate "Vendor Number" assigned by the Public Welfare Division, sign the invoice, and enter the date the invoice was signed. 


\section{Welfare Clients Age 65 and Over, \\ Enrolled Under Title XVIII, Medicare, Part "B", \\ Voluntary Supplementary Medical Insurance (SMI)}

Welfare clients enrolled in Supplementary Medical Insurance, hereafter referred to as SMI, are covered for ambulance services, subject to the rules and regulations established under SMI, the $\$ 60$ deductible, and the $20 \%$ coinsurance. Aetna Life and Casualty is the insurance carrier for Part "B"。

\section{Authorization, Billing and Payment Procedures}

1. Billing form used by ambulance companies is SSA-1490W(OR), Request for Medicare Payment, Exhibit 非. This form is available in quantity from Aetna Life and Casualty。

Form SSA-1490W(OR) serves a double purpose for clients covered by Part "B" Medical Insurance and Welfare. Mail this form to Aetna Life and Casualty and not to Welfare. Clients under age 65 or those 65 years of age and older not covered by SMI are to be billed to Welfare on the PWD-501B. For those 65 years of age and older and not covered under SMI the carrier will state on the face of the PWD-501B, "This person not covered under SMI".

\section{A. Cases not Prior Authorized}

Aetna Life and Casualty processes the SSA-1490W(OR), forwards the form together with its explanation of payment to the Public Welfare Division which in turn forwards the material to the Public Welfare Branch Office. The Public Welfare Branch Office then acts on the invoice in the same manner as it presently acts upon an ambulance company request for issuance of a PWD-501B; i.e., evaluates the medical justification, and rejects, approves, or modifies the service and charge within the limitations and under the rules and regulations detailed elsewhere in this guide, including availability of funds to cover justified services. Authorization of medical transportation service authorizes payment of the deductible and coinsurance within the rate limitations set forth elsewhere in this guide. Authorization for payment will not be given if adequate funds for obligation are not available.

If the ambulance trip is a service covered by Aetna Life and Casualty and Aetna reduces the charge for the covered service, PWD will not make up the difference between the original charge and the reduced charge. PWD participation is limited to the deductible and/or coinsurance calculated by Aetna against the reduced charge.

If the service/charge is approved, the Welfare Branch Office returns the salmon copy of the SSA-1490W(OR) to the Public Welfare Division for payment. Under the column headed "Leave Blank" on the 1490W(OR), 
the Welfare Branch Office must certify for payment the unpaid balance approved by the Welfare Branch Office.

If the service and/or charge is rejected, the Public Welfare Branch office returns the SSA-1490W(OR) to the ambulance company with an explanation.

\section{B. Cases Prior Authorized}

Where the Public Welfare Branch Office has prior authorized medical transportation for a Welfare/SMI client, billing will be done on the SSA-1490W(OR) and processed as described above under " $A$ "。 Prior authorization of medical transportation service authorizes payment of the deductible and coinsurance within the rate limitations set forth elsewhere in this guide. Prior authorization for payment will not be given if adequate funds for obligation are not available.

2. Completing Form SSA-1490W(OR). Aside from completing the form in detail for billing purposes, two important items must always be shown:

a. The ambulance company's Welfare vendor number must be entered in the block for "Physician's or Supplier's Code" near the bottom of the form, and

b. A notation must be made as to where the trip started and the destination. A copy of the public billing attached to the invoice will provide this and other detail. 


\begin{tabular}{l} 
WELFARE COMPLETE \\
\hline STARTING POINTAND DESTINATION \\
(CHECK ONLY QNE BOX) \\
FROM: N DOCTOR'S OFFICE/CLINIC \\
B $\square$ U OF O MEDICAL SCHOOL HOSPITAL \\
C $\square$ U OF O MEDICAL SCHOOL CLINIC \\
$D \square$ MULTNOMAH COUNTY HOSPITAL \\
E $\square$ HOSPITAL INPATIENT \\
F $\square$ HOSPITAL OUTPATIENT \\
G CONGREGATE CARE FACILITY \\
$H \square$ PRIVATE HOME \\
$I \square$ DRUGSTORE \\
$J \square$ OTHER (DESCRIBE)
\end{tabular}

TO: (CHECK ONLY ONE BOX)

$A \square$ DOCTOR'S OFFICE/CLINIC

$B \square$ O O MEDICAL SCHOOL HOSPITAL

C $\square$ U OF O MEDICAL SCHOOL CLINIC

D MULTNOMAH COUNTY HOSPITAL

E $\square$ HOSPITAL INPATEINT

F $\square$ HOSPITAL OUTPATIENT

G $\square$ CONGREGATE CARE FACILITY

H PRIVATE HOME

$1 \square$ DRUGSTORE

$J \square$ OTHER (DESCRIBE)

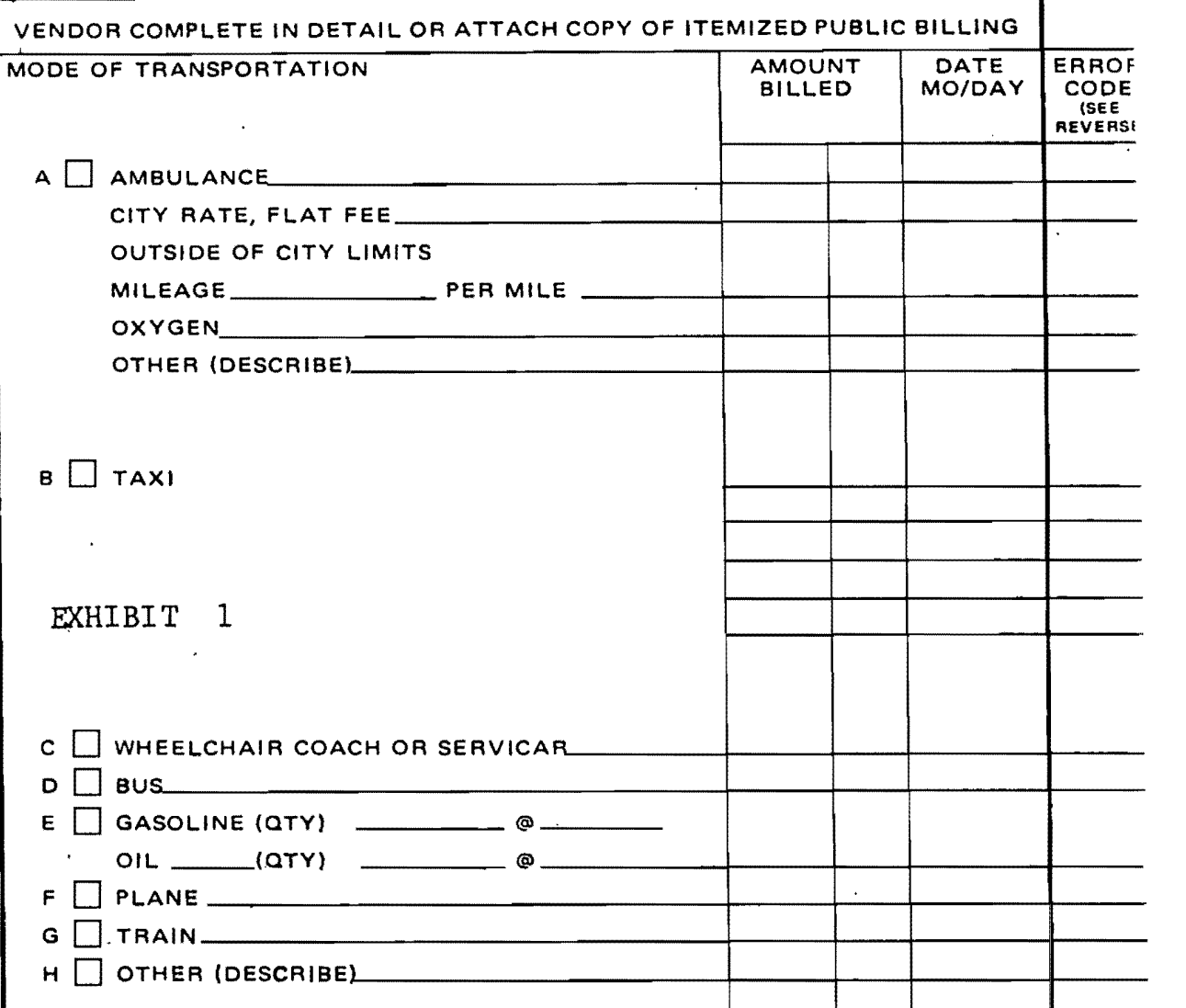

R $\square$ AND RETURN

\section{THIS SECTION COMPLETED BY CPWD OR AMBULANCE COMPANY}

WERE THESE SERVICES REQUIRED AS A

RESULT OF AN ACCIDENT OR INJURY?

IF YES, WHICH TYPE?

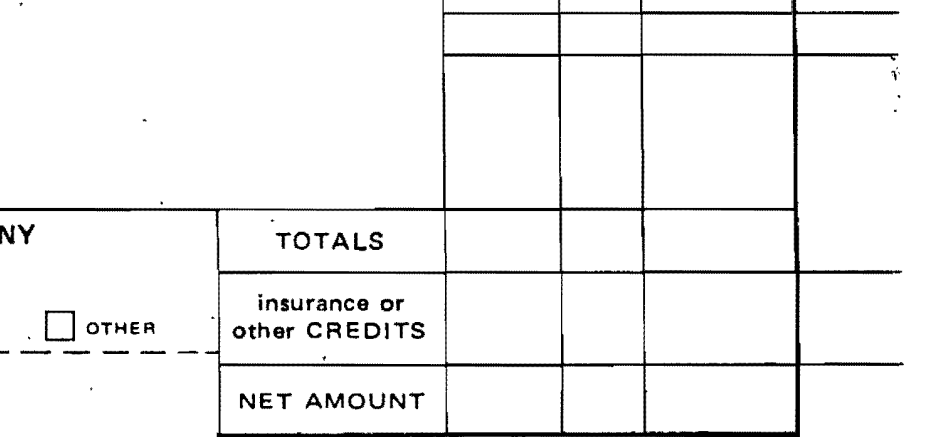

Error Code applicable to

other than billed items.

I CERTIFY THAT the goods or services described in this invoice were rendered to the person named herein according to Oregon law and the Rules and Regulatio of the Public Welfare Division; that payment has not been received except as noted; that payments which may be received from any other source will be reimburs to the PWD; that such records will be retained as are necessary to disclose fully to the PWD the extent of services provided to the person named herein; that inf: mation regarding any payment claimed in this invoice will be made available, upon request, to the PWD within the limitations stated in Oregon law; and that $t$ foregoing jinformation is true, accurațe, and complete.

I UNDERSTAND THAT payment and satisfaction of this claim will be from Federal and/or State funds, and that any false claims, statements, or documents, । concealment of a material fact, may be prosecuted under applicable Foderal or State laws.

Date Signed. 
Medicare Claim Administration 300 Yeon Building Portland, Oregon 97204 222.6831
1. Name of potient (Must be age 65 , or over)

2. Claim Number (Copy from his Medicare Card)

3. Street Address, City, State, Zip Code
I. Mole Ljomale

Tolephon Number

5. Show name and address of facility where services were performed (If other than home or office visits)

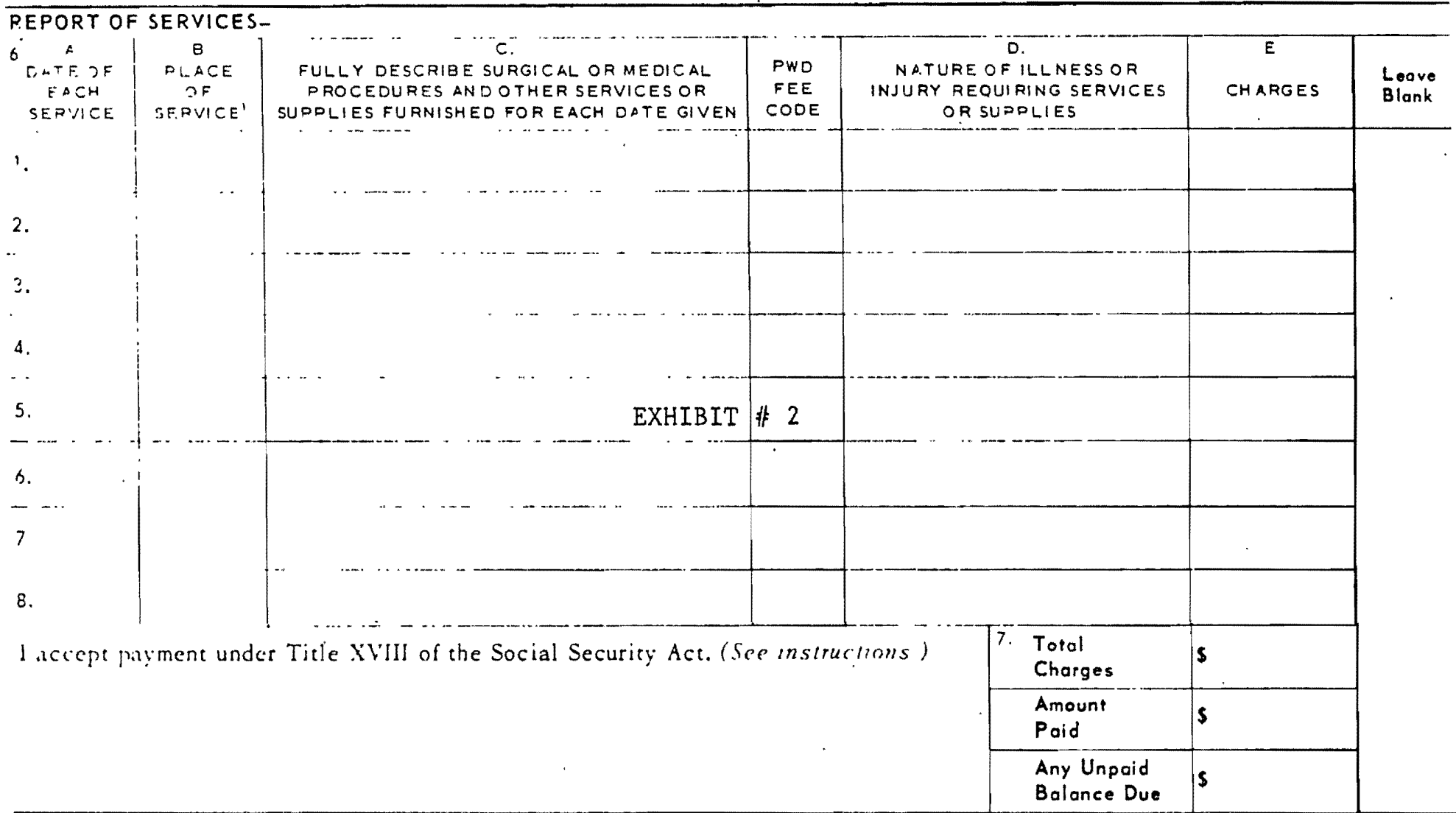

SHADED AREAS FOR USE OF STATE MEDICAL ASSISTANCE PLANS ONLY AND IS NOT REQUIRED BY THE

\begin{tabular}{|c|c|c|c|c|c|}
\hline PROGRAM & COUNTT & CASE NUMBER & PERS LETTER & DATE & SERIAL NUMBER \\
\hline
\end{tabular}

$I$ certify that the goods or services described in this invoice were rendered to the persons named herein by myself or under my personal direction according to Oregon Law and the Rules and Regulations of the Oregon PWD; that payments which may be received from any source (other than those received from Title XVIII-Part B-Intermediary as a result of this billing) will be

4. Was your patients' illness or injury connected with his employment?

I. Yes $L]$ No SOCIAL SECURITY ADMINISTRATION

PÜBLIC ASSISTANCE IDENTIFICATIONN (COPY from PA identification cord) reimbursed to the Oregon PWD.

NAME OF OTHER PHYSICIANISI BILLING IN THISCASE

B Npmp ond address of physicion or supplier (Number and street, City, State, ZIP Code)

9. Signoture of physicion or supplier (A physicion's signature cersifies that physicion's Services were personally 


\section{INSTRUCTIONS TO PHYSICIAN OR SUPPLIER FOR COMPLETING REPORT OF SERVICES}

Parmentu under Part $B$ of Title XVill of the Social

cecurity $A-1$ are based on the reasonable charge for pinisicians' services and medical supplies. Reasonable charges are determined by the organization which pays tive clarm. taking into account the customary charges na.e b; the phrsician or suppliet and the prevailing i..urges of physicians or suppliers in the area. The inysician or supplier accepting direct payment for scrices agrees to accept the reasonable charge as a) iull charee.

Fir cach date in item 2. the physician should indicate the piace of service. should describe any medical or itirgical procedure, attaching a supplementary statement if necessary, and should describe the illness or injury being treated. If more than ore procedure or treatment was frovided on a single date, describe each procedure separately. Include any charges for preoperative and fostoperative care in surgical charges.
Where any charge is paid by the patient, a standard form SSA-1490. Request for Payment, shou:d be completed.

If the services or supplies were not furnished by a physician, the supplier should show in item 2D the name of the physician prescribing them. A report for ambulance service should show the origin and destination in item $2 \mathrm{C}$.

Space is provided for a physician or supplier identification number to idcilitate processing of the claim by the organization making payment.

The doctor or supplier may attach itemized or machineprepared bills which contain the same information required by item 2 of the form. The patient's claim number should be shown on each bill. The physician must show the nature of illness or injury requiring services or supplies either on the bill or in item 20 .

ITEMS RHIOU ARE FOR STATE NEDICAL ASSISTANCE HLANS ANI ARF NOT REQUIRFD BY THF: SOCIAL SECURITY ADUINISTRATION

\section{INSTRUCTIONS FROM OREGON PUB LIC WELFARE DIVISION}

This single billing form wall handle $\pi_{t}$-lfare patients 65 years or older who are also beneficiaries under Medicare's Voluntary Supplementarv. Mcedical Insurance (SMIB).

1. Send this bill we Aena of patient is enroHed or if there is a possibility that he is enrolled under SMIB. Identification is best made from the patient's Social Security Health Insurance identification card. Also, if thelfare records indicate that the patient is enrolled under SMIIB. "SMI" is printed in the Health Insurance column on the Delfare Modical Care Identification C.ard.

NOTE: If you are positive the patient is not enrolled under cylf bill Welfare direct on the regular pil)-501. Physician servace Invoice.

2 . In the column headed "PUD I:LE (CODE' enter the lielfare Procedure (ondes for each service billed.

3. Linder "CHARGES" hill your "usual and customary fees". NOT Welfare fers.

4. In the space at the bottom under "Physician's or supplier's Code" enter your Welfare Vendor Number.
5. Retain the last copy of this SSA-1490X', (OR) bill form and forrard all other copies to Aetna with carbons intact.

$\$ 50$ Deductible. If any portion of $\$ 50$ deductible is deducted from your bill. detna forwards trocopies of the SSA-1490W (OR) to Welfare. Welfare calculates its payment and retums a copy of the SSA-1490W (OR) to you.

20\% Coinsurance. If the $\$ 50$ deductible has been satisfied and only the $20 \%$ coinsurance factor is deducted, Aetna returns two cupies of the SSA-1490W (OR) to you. If Welfare owes any halance aftur comparing Aetna's paymen: with Weifare fees, enter Aetna's payment opposite "Amount Paid" on the SSA-1.190W (OR) and forward the two copies of the form to Melfare. Welfare calculates its payment and returns a copy of the SSA-1400W (OR) to you.

The Public Welfare Division can make payment only to the provider of service. Welfare CANNOT reimburse the patient nor include payment for medical services in the direct money payment to the client. 


\section{IIRTIFICATION FOR PAYMENT OF MEDICAL TRANSPORTATION SERVICES BY ORFGON PUBLIC WELFARE DIVISION AT PUBLIC RATES}

DETAILEI) BEL OII IS AN ITEMIZED SCHEDULE OF MEDICAL TRANSPORTATION SERVICES AND THE CHARGE FOR EACH OF THOSE SFRVICES. THESF, SERVICFS ARE CUSTOMARILY BILLED TO THE GENERAL PUBLIC AND THE CHARGES DO NOT EXCEED PUBLIC RATF.S.

THFSF CHARGFS ARE TO BE MADE EFFECTIVE RY THE PUBLIC WELFARE DIVISION ON MONTH DAY YEAR THIS DATF, IS NOT PRIOR TO THE DATE SUCH RATES ARE EFFECTIVE FOR THE GENERAL PURLIC.

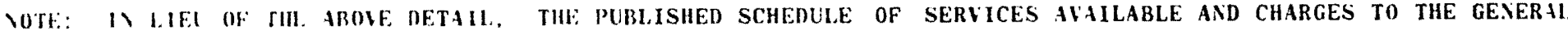
PIBLIC IRE ITTACILED AVD VADE A PART OF THIS CERTIFICATION.

EXHIBIT 3

IT IS AGREFT THAT THE RULES AND REGULATIONS GOVERNING MEDICAL TRANSPORTATION SERVICES, AS SET FORTH IN THE GUINF. FOR MEDICAI. TRANSPORTATION SERVICES, EFFECTIVE JULY 1, 1970, WILL RE FOLLOWED; AND THAT FURTHER ADJUST MENT IN RATES WILL, RE MADE IN ACCORDANCE WITH RULE FIVE OF THAT GUIDE. I HERERY CERTIFY THAT THE ABOVE RATES ARE NOT IN FXCFSS OF RATES CHARGED THE GENERAL PUBLIC, AND THAT I CUSTOMARILY CHARGE THE GENERAL PUBLIC FOR THOSE SERVICES AND AT THOSE RATES.

'I HERFRY CERTIFY THAT THF, AMOUNTS CLAIMED HEREIN DO NOT EXCEED THE MAXIMUM LEVELS ESTABLISHED IN ACCORDANCE HITH EXECUTIVE ORDER 11615, AUGUST 15, 1971, AS MODIFIED RY EXECUTIVE ORDER 11627, OCTOBER 15, 1971, AND ARE IN COMPLIANCE WITH THE PROVISIONS OF TITLE VI OF THE CODE OF FEDERAL REGULATIONS ENTITLED ECONOMIC STABILIZATION.'

D:ATEI) AND S(BBMTTTED THTS DAY OF 19

MIIF: AND ADDRESS OF CARRIFR:

OHNFR, NATACIER, OR OFFICER:

(signature)

NOTE: CIRRIFR TO FILE THF ORIFINAL COPY OF THIS CERTIFICATION WITH THE PUBLIC WELFARE DIVISION AND RETAIN A COPI: PIW ACREPTS THE SERVICES, RATES, AND DATES CERTIFIED ABOVE AND WILL CONTACT THE CARRIER ONLY IF TIIFRE IS I QI ESTION.

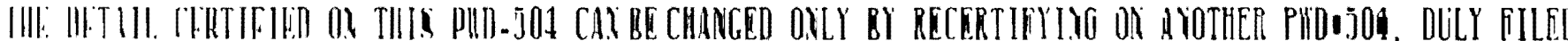
"ITH TH: PIBLIC WELFIRF DIVISION IN ACCORDANCE IITH RILE FIVE OF GIIDE FOR MEDICAL TRA.SPPORTATION ARIICES, MEDICAL ASSISTANCE PROGRAMS, PlbLiC WELFARE DIVISION, JULY 1, 1970. 